\title{
A aquisição do Present Perfect: um estudo de caso*
}

Aparecida de Araújo Oliveira

Programa de Pós-Graduação em Estudos Lingüísticos

Universidade Federal de Minas Gerais

Empregando uma abordagem orientada pelo significado e outra orientada pela forma em corpora de redações, entrevistas e role-plays, analisou-se a aquisição do present perfect por dezoito aprendizes brasileiros de inglês como língua estrangeira. Os dados revelaram duas categorias principais de situações, como concebidas pelos aprendizes - pertencentes ao passado ou ao presente -, em contraste com a moldura temporal contínua única, expressa pela forma alvo. Como indício de transferência de L1, observou-se uma forte tendência inicial ao uso de advérbios durativos em combinação com o past simple em contextos perfectivos de experiência, resultado atual e evento recente e em contextos de experiência imperfectiva. Esses recursos lexicais, os advérbios, também acompanharam o present simple e o present continuous nos contextos imperfectivos de continuação. Isoladas as dificuldades com a fonologia dos passados regulares, a emergência da forma alvo coincidiu, na maioria dos casos, com a fase final da aquisição do past simple. O recurso morfológico $H A V E$-ed foi empregado com maior sucesso em contextos imperfectivos de continuação, correspondendo ao uso do pretérito perfeito composto em português.

The acquisition of the present perfect tense by eighteen Brazilian EFL learners was analyzed by using meaning-oriented and form-oriented approaches on corpora formed with compositions, oral interviews and roleplays. The data yielded two major classes of situations, as conceived by the informants - belonging to the past or to the present -, which contrasted with the single, continual time frame conveyed by the target form. As a possible evidence of transfer from L1, there was a strong initial tendency to the use of durative adverbials in combination with the past simple in perfective contexts of experience, current result and recent event, as well as in those of imperfective experience. The use of adverbials as a lexical resource also occurred along with the present simple and the present

\footnotetext{
* Agradeço à Prof. Dra. Marianne Akerberg, da Universidad Nacional Autonoma de Mexico, por sua leitura paciente e minuciosa de meu manuscrito e por seus relevantes comentários sobre a categoria 'aspecto' nas línguas românicas.
} 
continuous in imperfective continuative environments. Apart from phonological issues related to the regular past, in most cases, target morphology emerged simultaneously with the final stage in the acquisition of the past simple. HAVE -ed was most successfully used in imperfective contexts which corresponded to the use of the pretérito perfeito composto in Portuguese, especially in contexts of continuation.

\section{Introdução}

É prática comum avaliar o processo de aprendizagem de um idioma estrangeiro por meio de testes escritos e descontextualizados que, a meu ver, são apenas um mecanismo simbólico e pouco eficiente para se aferir a aquisição propriamente dita. A diferença percebida entre o desempenho de meus alunos de língua inglesa em testes desse tipo e sua produção em contextos comunicativos levou-me ao estudo que agora apresento. Nele enfoco problemas na aquisição do present perfect $(P P)$, um modo de expressão da temporalidade particularmente difícil para aprendizes brasileiros. Essa dificuldade, em geral, transcende a morfologia e atinge a semântica do tempo verbal. A análise de entrevistas, role-plays e redações de aprendizes em diferentes estágios de interlíngua (IL), com a devida categorização dos dados em função dos padrões de uso/não-uso em contextos específicos, permitiu-me construir um retrato sistematizado dos sentidos que os aprendizes geralmente associam à forma do $P P$ e demonstrar como essas relações simbólicas variam em função da aquisição da morfologia temporal como um todo e de mecanismos lexicais envolvidos na expressão da temporalidade.

Da comparação entre a língua portuguesa, a língua alvo (L2) e as amostras de IL, surgiram fortes indícios da interferência da língua materna (L1) na formação de esquemas, ou sentidos, associados às formas lingüísticas. Temos, então, que a aparente conveniência inicial de considerarmos o tempo um conceito universal se desfaz ao percebermos que ele pode ser tratado de modo diverso em idiomas distintos. Uma abordagem a essa questão - a que assumo neste trabalho - é de que língua e cultura estão irremediavelmente unidas, ou seja, diferentes visões de mundo e componentes diversos da vida cotidiana são incorporados aos significados subjacentes às formas de cada língua, 
implicando modos particulares de lexicalização e gramaticalização, nem sempre arbitrariamente. Embora, de um modo geral, nos idiomas mais estudados, o conceito de tempo venha acompanhado da noção de aspecto, nem sempre são as mesmas classes de palavras que os expressam. Assim, mesmo que advérbios e verbos muito freqüentemente se refiram à temporalidade, a morfologia verbo-temporal, em especial, varia enormemente entre idiomas.

Como reflexo dessa diversidade, aprender um idioma novo implica, também, conhecer conceitos de uma nova cultura. Com relação ao sistema aspecto-temporal em particular, o que normalmente se observa é uma dificuldade maior com a aquisição da semântica verbal, isso porque, segundo Klein (1986, p. 5), embora conceitos - ou categorias cognitivas - formados na primeira infância, antes e durante a aquisição da primeira língua, sejam úteis para a aquisição de uma segunda, muitas vezes o conceito existente precisa ser "modificado" e "reajustado", o que constitui um desafio para o aprendiz. Outra afirmação de Klein a respeito da L1, mas que pode ser estendida à aquisição de qualquer idioma, e com a qual nós, professores, facilmente podemos concordar, é de que formas gramaticalmente corretas não implicam, necessariamente, um conhecimento pleno da língua: "o falante pode dar a seus enunciados um significado bem diferente". ${ }^{1}$ Mesmo em face de conclusões do senso comum, faltam estudos que identifiquem, de maneira sistematizada, as dificuldades encontradas pelos aprendizes brasileiros, "devidas à interferência do português e a outros tipos de interferência" (GOHN, 1981, p. 82). Assim, com base nas duas afirmações de Klein mencionadas acima, busco, através desta investigação, demonstrar a desproporcional dificuldade encontrada por falantes nativos de português brasileiro em adquirir a semântica do $P P$ da língua inglesa, em comparação à sua morfologia.

Um tipo de comportamento comum entre aprendizes brasileiros, inclusive aqueles em níveis mais avançados, é fazer uso dos marcadores

\footnotetext{
${ }^{1}$ No original: "The production of grammatically well-formed utterances does not mean that the speaker has mastered the language; he may endow these utterances with quite a different meaning. Secondly, the speaker must have acquired the cognitive categories which underlie the various expressive means of natural languages - categories such as time, space, modality, causality, etc." (KLEIN, 1986, p.4).
} 
lexicais ever, before, since, for, just, already, ago, last, etc., presentes no texto, ao escolherem o tempo verbal a ser empregado. Enquanto se trata de uma estratégia inteligente por parte do aluno, pode se converter em problema, caso seja levada ao extremo, como alertam El-Dash e Busnardo (2002, p. 67), ao avaliarem que o desconhecimento da semântica verbal nos dois idiomas tende a criar dificuldades para falantes de português, aprendizes de inglês. ${ }^{2}$ Minha primeira hipótese foi, então, a de que o problema enfrentado pelos aprendizes com relação a esse tempo verbal se deve ao fato de que, inicialmente, eles associam a forma do $P P$ apenas ao significado de duração (aspecto imperfectivo), ignorando totalmente os contextos de aspecto perfectivo (concluído), nos quais a forma expressa uma ligação mais sutil entre passado e presente. A segunda hipótese foi a de que o fenômeno se intensificaria na IL à medida que pistas contextuais para o emprego do $P P$ se tornem menos óbvias. Inspirando-me em estudos multilíngües de Bardovi-Harlig (2001) sobre a aquisição da temporalidade, meu objetivo foi demonstrar como diferentes distâncias entre conceitos em L1 e L2 geram efeitos na ordem de aquisição de uma mesma forma, em função do contexto de uso.

As categorias semânticas de tempo, aspecto morfológico e aspecto lexical (significado objetivo do verbo - termo Langackeriano para aktionsart) envolvem a temporalidade de modos diferentes, embora estejam intimamente ligados. Por essa razão, também compuseram a base para a delimitação de categorias semânticas perfectivas e imperfectivas - ou significados do PP - encontradas nos dados.

Nas duas seções seguintes, apresento um resumo da literatura sobre esse tempo verbal e sua contraparte em português. Lembro, entretanto, que as formas e os significados apresentados aqui não representam todo o conjunto de possibilidades de que os dois idiomas dispõem para os fins propostos.

\footnotetext{
${ }^{2}$ Segundo essas autoras, "os brasileiros que recebem instrução tradicional no inglês" tendem a relacionar automaticamente os advérbios já e recentemente em português (e os da língua inglesa citados acima) ao uso do present perfect em traduções para o inglês e, comumente, acrescentam um "already", nesses casos, enfático, para expressar o caráter de relevância atual já expressos pela morfologia do present perfect.
} 


\section{O present perfect}

O perfeito (present perfect, past perfect e future perfect) é uma forma perifrástica constituída por have $+V$-ed, que se distingue das demais formas verbais na língua inglesa por dois motivos importantes. Não se trata, necessariamente, de uma categoria dêitica, como na noção clássica de tempo verbal (LANGACKER, 1999a, 1999b), nem corresponde à elaboração da temporalidade interna de uma situação em qualquer momento, característica inerente à categoria aspecto (CELCE-MURCIA e LARSEN-FREEMAN, 1999, p. 110). O PP estabelece uma relação apenas indireta entre o tempo da situação anterior e o momento da fala (ou da relevância atual), através de um outro Ponto de Referência no tempo (PR), este sim, dêitico (COMRIE, 1976; LANGACKER, 1999a).

A busca por um sentido mais central para o tempo verbal se reflete na afirmação de Comrie de que informações adicionais sobre o aspecto de uma situação podem ser fornecidas por outras categorias que se associem ao perfeito, por exemplo, o progressivo. Como a morfologia do perfeito não oferece indicações de perfectividade ou imperfectividade, Friedrich ${ }^{3}$ (apud Li et al., 1982, p. 66) o categoriza como um terceiro aspecto ou, nas palavras de Celce-Murcia e LarsenFreeman (op. cit. p. 110), formalmente oposto ao simples e ao progressivo e mesmo à combinação do perfeito-progressivo.

Paralelamente, sentidos mais específicos têm sido atribuídos à forma do $P P$, mas esses não derivam exclusivamente do perfeito, como o "resultativo" ou de "relevância atual" - situação passada com resultado presente, "continuativo" - situação iniciada no passado e persistindo até o presente, "de experiência" - situação que ocorreu uma ou mais vezes antes do presente momento, "de passado recente" - situação ocorrida no passado recente (BRINTON, 1988, p. 10), "anterioridade" (CELCE-MURCIA; LARSEN-FREEMAN, 1999, p. 115) e, ainda, "possibilidade de o evento ainda vir a acontecer" (LANGACKER, 1999a, p. 212). Para Brinton (op. cit. p. 14-5), entretanto, fica claro que o PP não expressa, essencialmente, a noção de "completude", sentido esse associado ao aspecto perfectivo:

${ }^{3}$ FRIEDRICH, Paul. On aspect theory and Homeric aspect. In: IJAL, 40.4, Part 2, Memoir \#28, 1974. 
“(...) o significado de 'completude' deve ser visto como uma implicação, mas não uma parte essencial, do significado do perfeito; em vez disso, é função do perfectivo/imperfectivo expressar a distinção completo/incompleto. O perfeito [PP] retrata uma situação passada; esta é, normalmente, completa, mas não necessariamente. O perfeito não é incompatível com o significado de 'incompletude.."

Temos, então, que a percepção e a compreensão do significado do sistema aspecto-temporal de um idioma requerem uma investigação do texto e não apenas do contexto oracional (LARSEN-FREEMAN et al., 2002, p.4). Nos exemplos abaixo, retirados de corpora de correspondência pessoal e textos jornalísticos produzidos por falantes nativos de inglês norte-americano (OLIVEIRA, no prelo) e analisados com base nos estudos de Gero Bauer, Robert McCoard e Howard Garey (apud Brinton, op. cit., p. 41-51), ${ }^{5}$ podemos perceber como outros elementos do contexto (entre eles, o aspecto lexical e os argumentos do verbo) se alinham, gerando o sentido específico da relevância. Por vezes, entretanto, a distinção não é transparente.

(1) '...preventing us from getting our hands on people who are responsible for what's gone on in Afghanistan will find the United States not terribly friendly to their aspirations," he said. The use of proxies has had clear advantages. It enabled American forces to wage the war by carrying out airstrikes and dispatching commandos with limited numbers of conventional forces. The bulk of the ground fighting was done by the Afghan allies themselves.' (The New York Times online - 18.12.01)

(2) 'We've just spent our month of vacation in Hawaii. It was absolutely wonderful to have R., Pm., Rs. and Sr. there for 2 weeks. Both children learned to use snorkels and were delighted with the hundreds of beautiful fish to be seen at Hanapeiu Bay Beach.' (Correspondência pessoal)

\footnotetext{
4 “(...) the meaning of 'completion' must be seen as an implication of, but not an essential part of, the meaning of the perfect; rather, it is the function of the perfective/imperfective to express the distinction complete/incomplete. The perfect portrays a past situation; this is normally, but not necessarily, complete. The perfect is not incompatible with the meaning of 'incompletion'."

${ }^{5}$ BAUER, Georg. The English 'perfect' reconsidered. Journal of linguistics. 6:189-98, 1970; GAREY, Howard. Verbal aspect in French. Language, 33, p. 91-110, 1957; McCOARD, Robert W. 1978. The English perfect: tense-choice and pragmatic inferences. (North-Holland Linguistics Series, 38) Amsterdam: North Holland, 1978.
} 
(3) 'We have been awaiting news of a place for us in Virginia that would be a perfect distraction for me. It is a 2-story farmhouse with wood burning stoves nestled on 50 acres of forested meadowlands with an existing dog yard fenced in. I enjoy the 18-acre place I currently live at but have already' (Correspondência pessoal)

Em (1), mesmo sem um advérbio explícito (since... ou for...), o contexto aponta para uma guerra ainda em andamento. Um verbo atélico (que descreve uma situação sem um ponto final ${ }^{6}$ ) como have e a natureza duradoura do argumento advantages produziriam o PP de situação que persiste até o presente. ${ }^{7}$ Ou poderíamos cogitar múltiplas vantagens, usufruídas em ocasiões variadas, determinando o PP de experiência repetida, mas, de qualquer maneira, é o auxiliar have (no presente) que determina que as vantagens ainda são desfrutadas, como demonstrado na comparação com The use of proxies had clear advantages. Em (2), é just (recently expressaria significado semelhante) que acrescenta a noção de fato recente à predicação, cujo significado seria $P P$ de experiência na ausência do advérbio. Como lembra Comrie (1976, p. 55 e 60), a proximidade do presente, por si só, determina a relevância presente. E, além disso, ainda segundo o autor (p.55, n.1), o PP pode introduzir um fato novo, o qual, uma vez compartilhado por falante e ouvinte, desenvolve-se por meio do perfectivo, como em learned acima. Como nos outros casos, em (3) o PPapenas determina a relação temporal com o presente. O verbo perfectivo await (esperar por algo), de atividade atélica, com o argumento também atélico news (substantivo incontável em inglês), produz o PP de experiência na forma simples "We have awaited..." (Nós [já] esperamos por...). BE + ING, no entanto, representa uma situação imperfectiva ou homogênea no decorrer do tempo até o momento da fala (situação persistindo até o presente), o qual é mencionado mais adiante - "I enjoy the 18-acre place I currently live at" (Eu gosto dos 18 acres de terra em que vivo atualmente).

\footnotetext{
${ }^{6}$ Comparando "Marcos está cantando" com "Marcos está cantando uma canção", temos que a primeira situação é atélica, porque Marcos poderá interromper o processo a qualquer momento e, ainda assim, 'terá cantado'. Na segunda situação, classificada como télica, Marcos não 'terá cantado uma canção’ enquanto não chegar ao final dela.

${ }^{7}$ Classificação tradicionalmente empregada nas discussões sobre o $P P$ em inglês, como se vê em Comrie (1976, p. 56-61).
} 


\section{Distinções importantes entre o português e o inglês}

Se tomarmos como referência a existência de marcadores formais, temos que o sistema verbal do português (CÂMARA Jr., 1970) se apóia em um eixo modo-temporal, com poucas desinências próprias de aspecto, exceto pelo imperfeito, construções com o gerúndio e o particípio ou por certos sufixos (-itar, -icar). Outras características aspectuais são instanciadas através de um sistema verbal especial, constituído por perífrases compostas de verbos de ligação e formas do particípio ou gerúndio, e por verbos como começar (a), ir, vir (de) e acabar (de) e seus equivalentes semânticos (COSTA, 1997; ALMEIDA, 1980).

Na língua portuguesa, a forma correspondente ao $P P$ é o "pretérito perfeito composto": ter ou haver (presente) + particípio passado. Semelhantes na morfologia, nem sempre essas duas construções incorporam o mesmo sentido. Analisando a questão da temporalidade, os exemplos abaixo demonstram que há uma relação necessária entre o passado e o presente, sendo este último PR, como ocorre com a forma inglesa. Porém, como se pode observar, em todos os exemplos a predicação é imperfectiva, persistindo até o momento da fala, seja por força da natureza objetiva do verbo (4), do argumento (5), pela habitualidade (6), ou pela iteração (7).

(4) - Você sumiu. Por onde tem andado?

- Ah, eu tenho trabalhado na minha dissertação e não tenho tido muito tempo pra sair.

(5) A chuva dos últimos dias tem causado muitos estragos nas rodovias do país.

(6) - A senhora tem tomado seus remédios regularmente?

(7) Nos últimos dias, o presidente tem recebido o ministro em seu gabinete para discutirem estratégias de combate ao crime organizado.

${ }^{8}$ COSTA, Sônia B. B. O aspecto em português. São Paulo: Contexto, 1997 apud El-Dash e Busnardo, 2002, p. 65. 
Por outro lado, essa forma não ocorre em combinação com predicações perfectivas para indicar um resultado atual decorrente de uma situação já encerrada, ou vista como tal: *João tem comprado um livro não é possível em português, devido à natureza limitada do argumento, mas, como destaca Mello (2002, comunicação pessoal), poderia ocorrer no caso de indefinição do objeto (por exemplo, 'livros' e 'carne'). A forma mais adequada seria, então, João comprou um livro (pretérito), que pode ser explicada pela afirmação de Corôa (1985, p. 53-4) de que, além do sentido de completude (ou cessação) anterior ao momento atual, o fato de o ponto de referência e o da enunciação coincidirem no presente implica um sentido de resultado atual, "pois o resultado é, no perfeito [perfectivo], muitas vezes mais importante que o próprio evento".

Comrie (1976, p. 20-1) faz colocação semelhante em relação ao perfectivo em geral, mas enfatiza que o sentido de resultado depende do significado objetivo de verbos individuais e que o conceito de 'resultativo' coloca ênfase "desnecessária no estágio final da situação". De todo modo, é o que parece ocorrer no exemplo (8), em que não se cogita a ação em si, mas as conseqüências atuais da mesma. Como destaca Berber Sardinha (2003, comunicação pessoal), os estados resultantes somente podem ser definidos através de um contexto mais abrangente, podendo incluir, tal como no exemplo abaixo, as condições de saúde de Zeca, ou apenas que o carro em questão seria o mesmo da viagem e, no momento, está avariado.?

(8) Eles não vão mais viajar porque o Zeca bateu o carro.

\footnotetext{
${ }^{9} \mathrm{Na}$ variedade norte-americana do inglês, um processo similar vem ocorrendo, em que uma forma do past (perfectivo) substitui a do present perfect, quando se trata de uma ação já encerrada, cujos efeitos ainda possuem alguma relevância (COMRIE, op. cit. p.53, n.2) ou quando a predicação expressa um acontecimento muito recente (CELCE-MURCIA e LARSEN-FREEMAN, 1999, p.123). Demonstra claramente essa tendência o exemplo a seguir, obtido do mesmo corpus de correspondência pessoal citado na p. 46, e no qual os nomes de pessoas são fictícios. "... Well, I think that catches you up on all our news. Ijust finished a letter to answer Rita's and want to write Beth. She doesn't write much anymore... since she and Chuck were married."
} 
Da mesma forma, um evento concluído no passado próximo, traduzido comumente em inglês por $j u s t+P P$, não pode ser expresso pelo pretérito perfeito composto em português e é elaborado por intermédio de um advérbio e um verbo pontual no pretérito perfeito, como em Chegamosneste instante, ou por meio da perífrase acabar de, seguida por uma ação télica ou pontual no infinitivo: Acabamos de chegar (ALMEIDA, 1980, p. 89 e 221).

Com base na categorização proposta por Harris $\left(1982^{10}\right.$ apud Squartini e Bertinetto, 2000), as restrições descritas acima enquadram o português, juntamente com o galego e diversas variedades do espanhol americano, no segundo estágio de desenvolvimento dos pretéritos compostos das línguas românicas, a partir de uma forma latina com significado puramente resultativo, rumo a um sentido de passado perfectivo. No primeiro estágio, o pretérito composto apresenta baixo nível de gramaticalização e também é utilizado apenas para indicar o resultado atual de uma ação passada. No terceiro estágio ocorre uma profunda mudança em direção ao aoristo, ou perfectivo, em que há destaque para a noção subjetiva de relevância atual. Nos idiomas que se encontram no quarto estágio, o significado expresso pela forma é puramente perfectivo, já sem uma noção de distância relativa no tempo.

Langacker (1999b, p. 255-6) destaca, no presente da língua inglesa, o papel de expressar situações imperfectivas, a que ele atribui a incompatibilidade desse tempo com situações perfectivas em interpretações canônicas. Corôa (1985, p. 8-9, 73, 78-9) também destaca, no português, o potencial do presente para traduzir o "não-limite da ação", podendo, assim, "ser usado como expressão de qualquer dos dois [passado e futuro]". A diferença entre os exemplos abaixo está no caráter mais duradouro do primeiro:

(9) Eu resido aqui desde 1991.

(10) Eu estou residindo aqui $1991 .{ }^{11}$

\footnotetext{
${ }^{10}$ HARRIS, Martin. The "Past Simple" and the "Present Perfect" in Romance. In: VINCENT, Niguel; HARRIS, M. (Eds.). Studies in the Romance Verb. Londres: Croom Helm, 1982. p.42-70.

11 Exemplos que substituem os de Corôa, semanticamente não factíveis no contexto atual: 'Carlinhos trabalha no IBC desde 1965' e 'Carlinhos está trabalhando no IBC desde 1965'.
} 
Em Squartini e Bertinetto (op. cit. p. 428-9), lemos que o emprego do presente com verbos de atividade e com não dinâmicos (tradicionalmente denominados 'verbos de estado'), em situações que incluem o passado e o momento da fala, é um traço comum entre línguas românicas, por exemplo, no francês padrão: J'habite ici depuis longtemps (Moro aqui há bastante tempo).

Em vista das informações apresentadas acima, é possível partir, agora, para a descrição do trabalho de investigação propriamente dito.

\section{Participantes}

Os dados desta investigação foram coletados entre dezoito voluntários, alunos de inglês em dois institutos particulares de idiomas ou com um instrutor particular nas cidades mineiras de Divinópolis (dezesseis) e Leopoldina (dois), com idade entre 13 e $50^{12}$ anos e grau de instrução variando entre o ensino médio incompleto e o mestrado. Como previsto por Brown (1995, p. 31), a auto-seleção teve efeito benéfico na coleta de dados. Eram necessários, justamente, informantes mais motivados, mais autônomos e mais aptos para as tarefas e que produzissem o maior volume possível de dados. Em conformidade com o padrão nos estudos de aquisição, as conclusões deste trabalho se limitam ao grupo investigado.

O único pré-requisito para participar da pesquisa foi ter sido exposto à instrução formal específica sobre o tempo verbal investigado. Esse critério foi aferido pela análise do material didático e por meio de informações passadas pelos professores e, na verdade, é autoexplicativo, uma vez que a quantidade de insumo disponível fora da sala de aula mostrou-se insuficiente para que a aprendizagem pudesse ter ocorrido de maneira natural. O fato de nenhum dos estudantes ter relatado um contato direto com falantes nativos por mais de 100 dias ininterruptos - incomparáveis à residência permanente no país da L2, normalmente levada em conta nos estudos longitudinais - levou-me a considerar que a maior parte da aprendizagem decorreu do ensino formal, com duração entre três e nove anos à época da coleta. Alguns deles

${ }^{12}$ Ellis (1999, p.492) avalia que "The process of acquiring a language is not substantially affected by age, but that of acquiring pronunciation may be." 
foram admitidos nas respectivas escolas já no nível pré-intermediário, sendo impossível rastrear a data precisa do primeiro contato com a L2, tampouco havendo regularidade entre as variedades lingüísticas com que tiveram contato. Problemas dessa ordem são reconhecidos por BardoviHarlig (2000, p. 121) tanto em estudos longitudinais quanto transversais. Para lidar com a situação, os aprendizes foram distribuídos em cinco faixas de IL (O\%, 1 a 20\%, 21 a 40\%, 41 a 60\% e 61 a 80\% de adequação), em função dos próprios dados obtidos, de acordo com sua competência no uso da morfologia e semântica verbais. Essa decisão acrescentou à pesquisa características de um estudo pseudolongitudinal, aumentando as possibilidades de conclusões quanto à IL como processo, mesmo que restritas ao grupo participante.

\section{Coleta dos dados}

O maior interesse neste estudo foi observar a emergência do $P P$ na IL, em comparação com outros tempos verbais. Isso foi possível a partir de dados produzidos em situações de fala - entrevistas e role-plays - e em uma redação, em vez de instrumentos mais fechados de coleta.

As entrevistas seguiram o modelo semi-estruturado descrito por Nunan (1994, p. 149), em que apenas o tópico é pré-definido. No caso específico deste estudo, o tópico pré-definido foi histórias de aprendizagem. Devido ao clima de informalidade das conversas, novos temas acabaram sendo inseridos, razão pela qual algumas gravações foram mais longas que o previsto, mas ficando, de um modo geral, dentro da faixa de 12 a 25 minutos.

Os role-plays ofereceram uma alternativa com maior grau de controle para a coleta de dados. Na verdade, essa modalidade de tarefa é comum em pesquisas de aquisição, por permitir que se diminua o volume de dados necessários (NUNAN, op. cit. p. 136; ELLIS, 1999, p. 160-3). Os participantes desta pesquisa interagiram entre si em seis role-plays ${ }^{13}$ do tipo aberto (DUTRA, 1998, p. 37), ou seja, construindo seu próprio

\footnotetext{
${ }^{13}$ Os papéis desempenhados por cada participante foram sorteados e o primeiro role-play de cada dupla foi descartado para minimizar os efeitos da inibição e da falta de familiaridade com o gravador.
} 
discurso a partir de situações que lhes foram apresentadas, criadas com base na literatura existente sobre o $P P$.

Redações geralmente fornecem bom material para o estudo da aquisição da temporalidade, seja através de diários, de ensaios, de composições livres ou baseadas em filmes (BARDOVI-HARLIG, 2000, p. 126-84), com o benefício extra de minimizar problemas de timidez entre os aprendizes. Meus informantes dispuseram de cerca de 30 minutos para produzir uma única versão de um texto com dois ou três parágrafos, a respeito de eventos recentes, sobre um dos seguintes temas: The Environment; Political Campaigns; Violence in large cities; Your favorite team's performance in the National Soccer League; War against terrorism, considerados atuais à época da coleta e, portanto, favoráveis à ocorrência de contexto de relevância atual.

Após a realização de pilotos com dois outros voluntários, os dados realmente empregados na pesquisa foram colhidos entre agosto e outubro de 2002, sempre em dois encontros: um para as atividades orais e outro para a redação. Houve um equilíbrio quantitativo na produção individual, exceto no caso de dois informantes (ver seção 6.1 abaixo), tendo sido analisadas 18 entrevistas individuais, 45 roleplays (cinco por cada par) e 17 redações, em horários escolhidos pelos participantes, em ambiente reservado, minimizando efeitos negativos de interrupções ou ruídos externos. As entrevistas e os role-plays foram gravados em fitas de áudio e transcritos imediatamente, após cada seção. Repetidas audições permitiram reduzir, próximo a zero, o número de trechos incompreendidos, e confirmar detalhes de entonação, interrupções e problemas com a pronúncia das formas, em especial, do passado e particípio de verbos regulares.

\section{Codificação de ocorrências}

Nos dados orais e escritos, foram consideradas como intenção de uso do PP as ocorrências de have/has e suas formas contraídas 's e 've antes de um verbo principal, sem levar em conta a concordância

\footnotetext{
${ }^{14}$ As morfologias aspecto-temporal e número-pessoal expressam sistemas semânticos distintos, sendo a última geralmente adquirida mais tarde (BARDOVI-HARLIG, 2000, p.113).
} 
de pessoa gramatical. ${ }^{14}$ Além das formas padrão, as tentativas de uso do present perfect progressive foram caracterizadas pela presença de have e suas variações, acompanhada de particípio presente (verbo ing) ou por have mais be um verbo principal, excluídos os casos de voz passiva. Desse modo, ocorrências como (11) e (12) foram marcadas como corretas quanto ao significado e incorretas quanto à forma.

(11) And have you ever... did some... like that? (Sérgio - role-play 4) - PP Simple

(12) The... the last months he has receiving a lot of visitors. (Paulo role-play 3) - PP Continuous

Quando houve interrupções e correções, foi tomada como parâmetro a última expressão empregada pelo informante. Já na impossibilidade de determinar sua intenção em relação ao significado e à forma, a ocorrência em questão foi descartada, como em (13).

(13) I: Is she still here?

L: No she... she has gone... one month ago... about... for a month. (Luisa - entrevista)

Em entrevistas, é comum encontrarmos o fenômeno que Nunan (1994, p. 150) denomina assimetria: a preponderância do entrevistador na produção de perguntas. Embora tal deficiência tenha sido suprida pelos role-plays, a grande maioria das incidências de $P P$ foi, realmente, encontrada na fala da pesquisadora e, em alguns casos, o informante apenas se limitou a fornecer uma resposta curta e objetiva ou que repetia a construção da pergunta. Ocorrências do gênero foram descartadas, pois não se pode afirmar, com certeza, que o emprego da forma tenha sido de total iniciativa do informante.

\section{Análise e discussão dos dados}

O processo de análise ocorreu em duas etapas, tendo sido encontradas 212 ocorrências (tokens), que deram origem a 162 tipos diferentes (types). Primeiro, em uma análise forma-função (ELLIS, 1999, p. 703) orientada pela forma, foi feita uma busca eletrônica (com o software Wordsmith ${ }^{\circledR}$ ) das instâncias de uso em contexto adequado 
ou inadequado (overuse). A outra etapa da análise, orientada pelo conteúdo, permitiu que fossem identificadas formas alternativas empregadas pelos aprendizes em contextos em que o $P P$ seria o mais adequado para inferir sobre hipóteses presentes em uma IL em processo (Von STUTTERHEIM e KLEIN, 1987). ${ }^{15}$ De modo a evitar que verbos reincidentes viessem a inflar os números (BARDOVI-HARLIG, 2000, p. 51 e 91, n.15), foi realizada uma análise conservadora, ou seja, apenas um exemplar de cada tipo foi computado, tendo sido considerados como instâncias de um mesmo tipo os casos em que uma mesma forma de um mesmo verbo principal ocorreu em dois ou mais contextos idênticos.

A análise das ocorrências permitiu duas classificações, que apresento a seguir.

Faixas de IL: compreende a distribuição dos informantes por faixas de desenvolvimento da IL em função da adequação do uso do tempo verbal.

0\% de adequação: incluem-se nesta faixa dois informantes que, mesmo já tendo sido expostos a input de $P P$, ainda não foram capazes de fazer uso da forma. Na verdade, ainda não dominam a morfologia do past simple, demonstrando dificuldade com a terminação-ed e as trocas de vogais internas na formação do passado.

De 1 a 20\% de adequação: os seis aprendizes dessa faixa usaram a forma alvo em uma ou duas ocorrências cada um. Cerca de metade deles ainda não domina a morfologia do passado, às vezes empregando a forma base, enquanto alguns se debatem com a forma do $P P$, como na tentativa malsucedida de repetição a seguir:

(14) I: Haven't you met anybody here in town or on a trip in... in Brazil?

O: No. I don't have meet anybody with I could talk in English. (Otávio - Entrevista)

\footnotetext{
${ }^{15}$ Von STUTTERHEIM, C.; KLEIN, W. A concept-oriented approach to second language studies. In: PFAFF, C. W. (Ed.). First and second language acquisition processes. Cambridge, MA: Newbury House, 1987. p.191-205 apud Bardovi-Harlig, 2000, p.22.
} 
De 21 a 40\% de adequação: apenas dois informantes, Sérgio e Lívia, pertencem a essa faixa, com uma produção média mais baixa (13 ocorrências) que a dos demais, o que desencoraja maiores conclusões. Por exemplo, o percentual elevado de acerto com imperfectivos (66,67\%) destoa dos índices observados nas demais categorias e, provavelmente, decorre da baixa produtividade individual. $\mathrm{Na}$ realidade, a mudança em relação à faixa anterior (25\%) deve ser menos brusca. Acredita-se que, pela mesma razão, foram geradas distorções na classificação desses informantes por faixa. Sérgio demonstra fluência bem maior e sua IL dá sinais de que o PP está emergindo após a consolidação do past simple, apesar de alguns poucos problemas formais. Lívia, por outro lado, ainda não consolidou a morfologia do past simple, embora já faça uso do PP. Formas em competição em diversos contextos causam algumas dificuldades de interpretação, como em (15), em que não há distinção morfológica entre a expressão de uma situação já encerrada e de outra em andamento.

(15) Li: I study English for six years in Antônio course and in my school...

I: Okay. And now... You said you studied with Antônio. Do you still go there?

Li: No.

(...)

I: But do you still study English?

Li: Yes. In S.. (Lívia - Entrevista)

De 41 a 60\% de adequação: três informantes encontram-se nessa faixa, atingindo níveis de correção mais altos e mais homogêneos no uso do past simple. Como um todo, eles apresentaram um salto quantitativo no uso da forma em contextos perfectivos (experiência - 70\%; resultado atual - 50\%; evento recente - 66,67\%).

De 61 a 80\% de adequação: nesse subgrupo encontram-se cinco aprendizes com elevado índice de correção nas formas verbais empregadas de um modo geral e de emprego da forma alvo (84\%) em contextos imperfectivos de continuação. Além disso, vem dessa faixa a única instância de uso adequado da forma no contexto de experiência imperfectiva:

(16) I've always heard him play his piano. (role-play 3 - Rita) 
Categorias semânticas: A partir de categorias já estabelecidas na literatura sobre a L2, os dados foram distribuídos em cinco grupos de situações perfectivas e imperfectivas, baseados no resultado da combinação da forma $P P$ com o significado objetivo do verbo, argumentos, advérbios e co-texto, representando situações de uso na IL. Como se percebe nos exemplos citados nos subtítulos Experiências perfectivas, Continuação e Experiências Imperfectivas abaixo, a categorização se deu por critério semântico e não pelo uso adequado da forma. Não se trata, contudo, de uma categorização a priori dos dados, mas de significados da L2 que se repetem na IL, todavia com algumas alterações. Assim, por exemplo, o tradicional significado de experiência foi desdobrado em perfectivo e imperfectivo e foram consideradas como experiências imperfectivas aquelas ligadas ao conceito de "a vida toda", que, na L2, são tratadas como continuação (ver explicação na categoria Continuação), mas que receberam, na IL, uma codificação distinta. Posto de outro modo, a categoria tradicional de continuação "perdeu" os contextos com essa duração temporal específica.

\section{Experiências perfectivas (Well, I never met an American, a native. - Pedro-entrevista): Com um total de 44 tipos, esse foi o} significado em que os aprendizes obtiveram o segundo maior percentual de sucesso entre os contextos perfectivos $(36,36 \%)$, iniciando na terceira faixa de IL $(33,33 \%)$ e saltando rapidamente para $70 \%$ na quarta faixa e $72,73 \%$ na quinta. A primeira ocorrência de $P P$ vem acompanhada do advérbio ever. Antes disso, só foram encontradas formas do passado simples, ${ }^{16}$ por vezes acompanhado de advérbios como yet, once e never. Essa tendência se expande entre as amostras dos aprendizes da quarta faixa, em que $87,50 \%$ dos usos do $P P$ surgem com um desses advérbios ( 7 casos), o que indica que a presença dos advérbios é facilitadora para os aprendizes em fase inicial de aquisição do tempo verbal. Já na última faixa, a forma e seu significado estão consolidados e desvinculados da presença de um advérbio explícito (62,50\%). Aliás, o conceito de 'experiência', em geral, parece ser

\footnotetext{
${ }^{16}$ Em dois casos, a forma base foi empregada: uma vez em contexto de encontro consonantal (act in a play) e outra, por um aprendiz que ainda está adquirindo as formas do past simple (speak BS + once).
} 
formado de maneira diferente da forma alvo, como se vê na discussão sobre experiências imperfectivas.

\section{Resultado atual (Some countries have developed programs of purification even it's more expensive than avoid the pollution of the fresh water. - Rita - redação): A forma alvo surgiu já nos} dados da segunda faixa de IL, em 18,75\% das ocorrências desse produtivo grupo de aprendizes. Atingiu o ápice de 50\% na quarta faixa e voltou a $44,44 \%$ entre os informantes da quinta faixa. Pode ser que o único caso de past perfect seja uma 'distorção' da forma alvo, mas isso não modifica o quadro. Exceto por already, presente em apenas três ocorrências, e yet, em uma, o contexto não pareceu muito favorável à presença de advérbios. É possível que essa seja a razão de o resultado atual apresentar o menor índice de uso da forma alvo entre todos os contextos perfectivos: 26,32\% em um total de 38 casos. Na ausência de um advérbio, a relação com o presente fica ainda mais abstrata e apenas o significado perfectivo fica em evidência.

Assim, não causa surpresa o fato de que o past simple seja, de longe, a forma preferida em todos os estágios investigados, aparecendo em 24 tipos, complementada por um uso da base e dois do present simple, que devem ter derivado da má formação do passado. Vale salientar ainda que em L1 esses contextos são expressos pelo pretérito perfeito, forma que também expressa contextos correspondentes ao past simple perfectivo do inglês, como discutido anteriormente sobre o exemplo (8): "Eles não vão mais viajar porque o Zeca bateu o carro". Assumo, então, que essa categoria cognitiva de L1 foi, de algum modo, influente na formação da semântica da nova língua sendo aprendida. Abaixo, apresento idealizações gráficas de esquemas representativos do $P P$ de resultado atual na IL em comparação com a L2. 

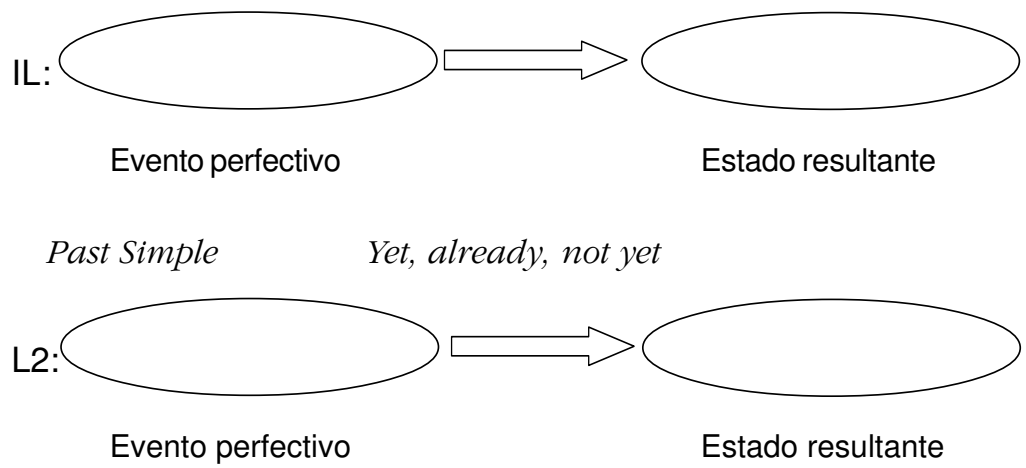

Have $+v$-ed

FIGURA 1 - Representação esquemática da elaboração da categoria "Resultado atual" nas primeiras fases da aquisição

\section{Evento recente (Flight number 203 has just arrived. - Rita-role-}

play 2): O tipo de relevância atual existente nessas situações é, segundo Comrie (1988, p. 60), unicamente a proximidade temporal com o presente. Trata-se do único caso, na língua inglesa, em que eventos com especificação de tempo passado podem ser expressos com o $P P$. Assim, a própria definição da categoria exclui as ocorrências sem advérbio explícito, limitando essa modalidade a apenas 16 dos 98 contextos perfectivos e apresentando um índice também modesto de emprego da forma alvo (37,50\%). A presença de advérbios não antecipou a entrada da forma alvo na IL e é possível, inclusive, que tenham reforçado a noção de completude. Instâncias de usos adequados (6) só surgiram nas duas últimas faixas, com índices de 66,67\%. De acordo com Walker (1997), não há distinção entre o past simple o o $P P$, quando na presença de just em referência a um passado imediato. Coincidentemente, foi mantido o padrão entre as situações perfectivas, com nove casos de past simple e um de present simple. 
IL:

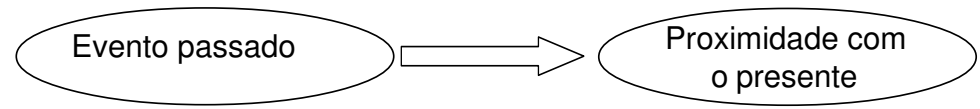

Past Simple Just, lately, recently

L2:

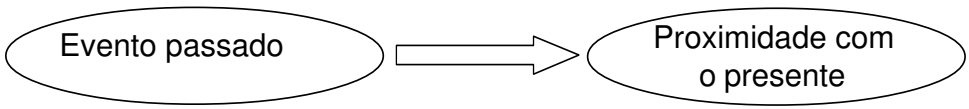

Have + v-ed-just, lately, recently

FIGURA 2 - Representação esquemática da elaboração da categoria "Evento Recente” no início da aquisição

Não podemos, então, afirmar, com certeza, que se trata de um caso claro de transferência lingüística, visto que um evento concluído no passado próximo é expresso, em L1, não só por meio de um advérbio e um verbo no pretérito perfeito, mas também por uma perífrase (ver seção Distinções importantes entre o português e o inglês). É provável que todos esses elementos - presença de advérbios específicos, exposição às duas formas da L2 e alguns esquemas de L1 - participem na dinâmica da IL nesse momento.

Continuação (I don't have I computer until it. - Otávio entrevista): A união de três significados mais específicos (habitualidade, iteração e duração) em uma única categoria foi baseada na classificação de Bauer e McCoard, citada na seção O present perfect. Com isso, o número de ocorrências válidas por tipo chegou a 54. No início, 100\% dos casos foram expressos pelo present simple ou continuous, junto com um advérbio de duração. Em geral, informantes de todas as faixas empregaram essas formas, 20 vezes com advérbio durativo e apenas 5, sem. Como ocorre em português, os aprendizes provavelmente se basearam no caráter atemporal do primeiro e na efemeridade ${ }^{17}$ do segundo, implementando a relação entre dois pontos no tempo por meio

\footnotetext{
${ }^{17}$ A distinção entre os dois significados é bastante sutil nesses contextos e não incorpora o objetivo da análise.
} 
de advérbios que se traduzem por since..., for..., how long e suas variações *how much time, *how many years. Na L2, o conceito é estabelecido somente pela morfologia verbal e a presença do advérbio apenas modifica o significado geral de "experiência" para "continuação".

(17) He has lived in Iraq and Saudi Arabia.

(18) He has not lived there since the outbreak of the war.

O uso de formas do passado ( 7 ao todo) destoa do padrão, e teve razões peculiares. Uma das ocorrências, no progressivo, foi, muito provavelmente, fruto de descuido, tendo em vista que foi produzida por uma informante que já emprega a forma estudada com grande domínio. Já as três ocorrências de past perfect simple apareceram no corpus de um único aprendiz - Fernando -, em estágio inicial de aquisição. A falta de contextos obrigatórios de past perfect próibe a afirmação de que as duas formas sejam usadas livremente, o tempo todo. ${ }^{18}$

(19) Attacks with biological weapons had been more normaly today. (Redação)

Uma ocorrência de past simple deu-se com o advérbio today. Essa moldura de tempo pode ser interpretada de modo variável: ou se considera o dia encerrado, caso em que o past simple é adequado, ou ainda em andamento, com preferência pelo uso do PP(WALKER, 1997, p. 19). No role-play 5, vários informantes fizeram uso do past simple, mas havia pistas de que se tratava da primeira condição. No caso em questão, o informante deixou claro que a moldura temporal que incluía a situação ainda estava em aberto e, por isso, a ocorrência veio se juntar à categoria de continuação.

A forma alvo surgiu, pela primeira vez, nos dados dos aprendizes da segunda faixa, com $23,52 \%$, subindo para $66,66 \%$ na terceira (fato que deve ser desconsiderado, tomando-se em conta a reduzida quantidade de dados), voltando para $35,28 \%$ na quarta e consolidandose na última faixa, com $86,36 \%$ de acertos, sendo que os advérbios de

\footnotetext{
${ }^{18}$ O número maior de ocorrências em contexto imperfectivo, como em (19), em que formas do passado são bastante improváveis, aponta para uma competição apenas no nível formal e não no conceitual.
} 
duração acompanharam a forma simples do $P P$ em $77,78 \%$ dos casos e a forma progressiva em apenas $40 \%$. Assim, embora tenha competido mais tempo com formas do presente, o patamar de correção atingido foi bem mais elevado que nas formas perfectivas, em que o contexto de experiência estabilizou-se em 72,73\%, nas duas últimas faixas, enquanto os advérbios ainda parecem possuir um peso semântico importante nos contextos com o PP Simple.

Até sua estabilização, é provável que essa categoria seja interpretada a partir de uma perspectiva do presente. Mas, como visto na seção 2, formas do presente tendem a expressar uma atemporalidade latente, o que pode ter contribuído para esse tipo de elaboração. Todavia, uma hipótese não exclui a outra.

IL:

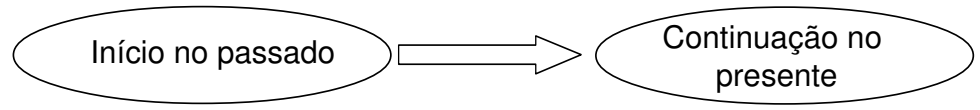

Since, for Present Simple/Continuous

L2:

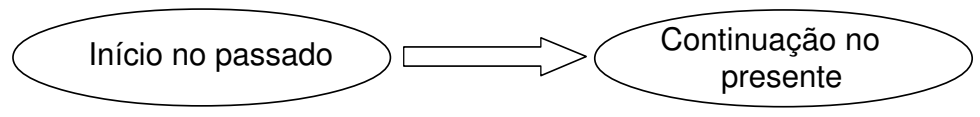

Have + v-ed (since, for)

FIGURA 3 - Representação esquemática da categoria "Continuação"

Experiências imperfectivas (I always studied bere in W. and I think I'm learning a lot. - Ione - entrevista): Apesar do número reduzido de ocorrências nesse contexto (apenas quatro), três delas surgiram na segunda faixa e foram expressas pelo past simple (duas) ou pela base (uma), seguidos por um advérbio durativo, como no exemplo abaixo.

(20) The terrorism was always used in the world to make people pay atention in the problems of a place. (Ione - redação)

Houve apenas um único acerto, na faixa 61 a 80\%, fato que corrobora a hipótese de que esses contextos são elaborados de uma maneira distinta na IL. Esse padrão sugere que, para esses aprendizes, 
experiências são sempre consideradas passadas, como qualquer situação perfectiva, e o sentido de continuidade é transmitido exclusivamente pelo advérbio. Há uma evidente diferença em relação à forma alvo, em que a noção de "a vida toda" imprime o mesmo significado que outros de duração em situações não dinâmicas, hábitos e iterações.

(21) We have known him since he was a child.

(22) She has always sung in the shower.

(23) The child has coughed all night.

(24) Jane has run for an hour.

Em resumo, as experiências são elaboradas na IL como dois tipos gerais de situação: pertencentes ao passado ou ao presente. Como em um estudo de Mello e Dutra (2000), a análise demonstrou, nesse e em outros contextos, a grande dependência de recursos lexicais, traduzidos para o português como já, desde então, até boje, etc., quando se sabe que, alguns deles apenas adicionam ênfase àquilo que a morfologia verbal já definiu.

IL:

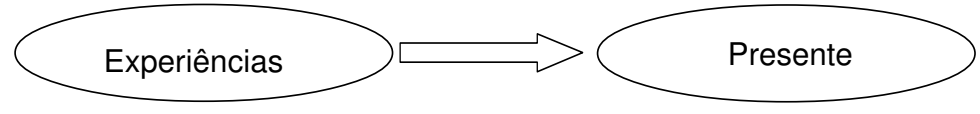

Past Simple Always, today, ever, never

L2:

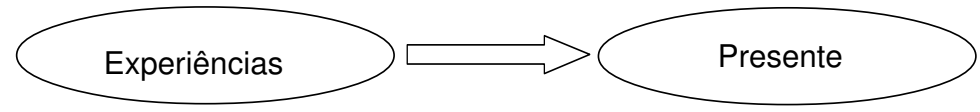

Have + v-ed (ever, never)

FIGURA 4 - Representação esquemática da elaboração do conceito de "Experiência" em geral, nos estágios iniciais

Overuse : Caracterizado pelo uso do tempo verbal em contexto não permitido, esse fenômeno complementa a compreensão dos esquemas de significados que os aprendizes vinculam a uma determinada forma. Entre os 6 tipos em 7 casos, há contextos complexos, outros pouco 
comuns, que somente são explorados após o PPna maioria dos programas de ensino. Dois deles se deram em contexto obrigatório de past perfect, em que PR é anterior ao presente, como no exemplo abaixo.

(25) When I studied here, I thought that I have learned a lot, but when I moved to... to England, I could see that I was not so good in my fluence [fluency]. (Silvia - entrevista)

Outros dois casos ocorreram em contexto de evento encerrado, sem ligação com o presente, o que determina o uso do past simple, como em (26) e devem derivar da mesma sutileza de significado que dificulta a aquisição em contexto obrigatório de $P P$.

(26) [...] I've started ... studying English by myself. I used to read... lyrics and then, I... I went to college in 1999... and started... learning at the university and then I went to a sch... a English school here in Divinópolis last year. (Paulo - entrevista)

No fragmento abaixo, a complexidade sintática e conceitual é a mais expressiva de todas, porque envolve a noção de que a experiência não mais ocorrerá, diferente portanto de "This is the first time I've visited the country." (WALKER, 1997, p. 18), quando ainda há expectativa de o fato se repetir.

(27) I'm sorry. It was a... the last time that it's happen. Sorry. It will never happen again. (Bruce - role-play 5 )

Finalmente, houve um caso observado de troca entre as formas simples e progressiva. A dificuldade era esperada, em função da pequena diferença entre os significados expressos por esses tempos verbais. O que impede o uso da forma progressiva é a presença do advérbio recently e o sentido de change, que pressupõe uma mudança única, que determina uma situação perfectiva.

(28) Do you realize if $M r$. Gray have change... have been change his routine recently? (Tiago 3 )

Erros formais: Tomando-se o número total de ocorrências efetivas da forma do $P P$ (61 tipos), verifica-se uma incidência de erros formais de apenas $19,67 \%$, o que demonstra que a aquisição do significado demanda mais esforço. Ao contrário, o tipo de erro formal mais comum 
não advém da dificuldade com a construção $H A V E+v$-ED propriamente dita (Tiago produziu a maior parte desses erros), mas da má formação do particípio, pelas mesmas razões da dificuldade com a aquisição da fonologia do past simple. Trata-se de um fenômeno comum, descrito por Anderson (1976 apud Ellis, 1999) ${ }^{19}$ em seu Modelo de Controle Adaptativo de Pensamento, em que o aprendiz conhece a relação forma-função, saberia escrevê-la, mas ainda é incapaz de produzi-la verbalmente.

A fonologia da L1 também pode dificultar a produção adequada de algumas formas, como identificou Wolfram (1984). ${ }^{20}$ Tal dificuldade com a morfologia do passado foi observada em todos os níveis, tanto na pronúncia de formas com consoantes mudas finais, quanto com mudança de vogal interna de passados irregulares, como [ri:d] e [red], [keim] e [k^m]. Em casos como os exemplos a seguir, considerou-se que a intenção do falante foi a de usar o passado, cuja fonologia não foi realizada, tendo em vista que a semântica e a morfologia desse tempo já haviam sido adquiridas para outros verbos.

(29) His house become a... spot... with lots of visitors... people coming and going every time. (Henrique - role-play 3 )

(30) Have you talk to him?['tokttə]

(31) Have you notice any changes in his routine nowadays? [noutst] (Luísa - role-play 3)

(32) I interrupt it a lot and so I... [Intər'^ptIdit] (Tiago - entrevista)

(33) I never traveled for another countries. (Fernando - entrevista: pronunciado [tr'æulid])

Alguns erros formais se deram claramente por transferência de L1, como a tradução literal abaixo. Como descrito na seção Distinções importantes entre o português e o inglês, em português é possível construir o sentido de duração até o presente usando meios morfológicos e lexicais associados: "Eu resido aqui desde 1991." / "Eu resido aqui há 14 anos.”

(34) And it arrived there's four minutes. (Marcos - Role-play 2)

\footnotetext{
${ }^{19}$ ANDERSON, J. Language, memory and thought. Hillsdale: Lawrence Erlbaum, 1976. ${ }^{20}$ WOLFRAM, W. Unmarked tense in American Indian English. In: American speech, 59, p. 31-50, 1984 apud Bardovi-Harlig, 2000, p.8.
} 


\section{Conclusão}

Retomando o que foi dito sobre o significado do PP na L2, salientase o fato de que ele expressa tanto situações imperfectivas como perfectivas, ou seja, concebidas com princípio (meio) e fim ou como uniformes no tempo. No caso das imperfectivas, é válida a definição de forma verbal que traduz "uma situação iniciada no passado e que continua até o presente". Tão arraigada parece estar essa idéia entre os informantes desta pesquisa, que o maior índice de sucesso foi observado nos contextos de "continuação". Ao se ensinar esse traço da língua inglesa, é preciso, entretanto, enfocar que não é, necessariamente, a situação que continua, mas a moldura de tempo em que ela está inserida. Só assim será percebido o sentido de "relevância atual" nas diversas modalidades que o PP ajuda a elaborar em construções perfectivas.

Uma descrição mais completa deveria incluir o modo singular como a categoria lingüística aspecto se manifesta nas construções com o $P P$, pois, de acordo com os dados, os aprendizes conceitualizam "continuação" meramente sob a perspectiva de tempo atual. Daí a razão do largo emprego de formas do presente para expressar esse sentido; afinal, esse é o significado central desses tempos verbais, especialmente na forma progressiva. De fato, mesmo quando o aprendiz demonstrou um alto nível de proficiência no emprego da morfologia alvo, houve uso episódico de present continuous nesse contexto, uso que encontra reflexo na L1: "Estou trabalhando aqui desde janeiro." Ao focalizar o início da situação no passado, unido ao momento presente, e observar que há uma morfologia verbal para transmitir esse sentido, sem depender do léxico, o aprendiz compreende a relevância do uso da forma, visto que nem o present continuous nem o present simple desempenham tal função.

É importante realçar que, na língua inglesa, o sentido de "continuação até o presente" incorpora também a noção de "toda uma existência" ou de um período de tempo cujo início é impossível de ser traçado. Assim, em vez de "The terrorism was always used in the world to make people pay atention in the problems of a place", o idioma alvo requer: "Terrorism has always been used in the world to make people pay attention to the problems of a place". Novamente, a forma alternativa escolhida não comporta esse significado. 
Com as situações perfectivas, ocorre um fato semelhante. Focalizando apenas a moldura temporal, "experiências concluídas", "eventos recentes" e "ações com resultado atual" pertencem tão somente ao passado, como previsto na primeira hipótese. Essa é uma constatação que vem do elevado índice de past simple nesses contextos, especialmente nos primeiros estágios da IL, e persistindo, menos intensamente, nos estágios seguintes.

Essa percepção equivocada da semântica de L2, apropriando-se de esquemas de L1, coincide com o fato de que o pretérito perfeito composto normalmente se limita a traduzir situações imperfectivas, iniciadas em época mais recente. Entretanto, essa é apenas uma parcela do que o $P P$ representa e, aliás, uma parcela daquilo que se convencionou denominar "continuação". Considero provável que essa semelhança tenha facilitado o maior índice de sucesso entre situações nessa categoria.

Nos estudos funcionalistas descritos por Bardovi-Harlig (2000), a aquisição da temporalidade é descrita em estágios: no início, um estágio nominal que não comporta verbos e emprega uma gama de estratégias pragmáticas; o segundo, denominado lexical, caracterizase pelo uso mais intenso do léxico, na forma de advérbios temporais e locativos, conectivos e verbos na forma básica; por fim, o estágio morfológico, com um incremento no uso da morfologia verbal e um decréscimo no uso de expressões adverbiais, tanto em número quanto na importância. Além disso, a IL se desenvolve em ciclos que incluem um retorno ao uso de expressões adverbiais toda vez que uma nova forma e um novo significado entram para a língua. É o que normalmente ocorre após a estabilização da morfologia do passado, quando o aprendiz começa a se referir a eventos passados anteriores, abandonando a dependência da estratégia de apresentar os fatos em ordem cronológica. A pesquisa com adultos revela um uso de adverbiais que, normalmente, não aparecem em estudos de aquisição de L1 por crianças. Contudo, o mais importante para o estudo foi a constatação do estágio denominado lexical, com uso mais intenso de advérbios temporais. Corroborando a segunda hipótese, foram eles que, nas faixas iniciais, acrescentaram, aos verbos no passado, a ligação com o presente (always, never, yet, ever) e, aos verbos no presente, a ligação com o passado (since..., for...). 
O mesmo caráter dinâmico da IL foi descrito no Modelo de Competência Variável (ver ELLIS, 1999), que postula que padrões abstraídos da língua em uso coexistem competindo entre si, de forma sistemática ou em variação livre, formando a IL em qualquer momento.

Fica demonstrado, então, que a idéia de uma ordem predeterminada para a aquisição de tempos verbais (morfologia e semântica) deve ser questionada, primeiro, em face das variações entre aprendizes de background lingüístico distinto; segundo, devido às diferenças individuais entre aprendizes; e, finalmente, levando-se em conta o contexto de aprendizagem formal, a que a maioria dos aprendizes no Brasil está sujeita, com programas que determinam a ordem mais ou menos comum em que os tempos verbais serão introduzidos.

Toda essa discussão demonstra que, caso se queira um retrato mais fiel dos processos de aquisição de uma língua estrangeira, é imprescindível verter o olhar para a real produção do aprendiz e levar em conta a gramática da L1, em uma perspectiva sintática, fonológica e semântica. Mesmo investigando apenas falantes de língua portuguesa, a análise dos dados confirmou que há fatores cognitivos e culturais gerando conceitualizações diferenciadas de uma mesma situação, influenciadas culturalmente. Espera-se, então, que os resultados alcançados inspirem novas pesquisas que co-validem ou refutem este estudo, uma vez que, tecnicamente, a influência da L1 carece de ser demonstrada investigando-se aprendizes de backgrounds lingüísticos distintos.

\section{Referências}

ALMEIDA, João de. Introdução ao estudo das perífrases verbais do infinitivo. Assis, São Paulo: ILHPA-HUCITEC, 1980.

BARDOVI-HARLIG, Kathleen. Another piece of the puzzle: The emergence of the Present Perfect. Language Learning, v. 51, p. 215-64, 2001.

Tense and aspect in second language acquisition: form, meaning and use. Malden and Oxford: Blackwell Publishers, 2000.

BRINTON, Laurel J. The development of English aspectual systems: aspectualizers and post-verbal particles. Cambridge: Cambridge University Press, 1988. 
BROWN, James D. Understanding research in second language learning. 5th printing. New York: Cambridge University Press, 1995.

CÂMARA JR. Joaquim Mattoso - Princípios de lingüística geral. $4^{\underline{a}}$ ed. $4^{\underline{a}}$ imp. Rio: Livraria Acadêmica, 1970.

CELCE-MURCIA, M.; LARSEN-FREEMAN, D. The grammar book-an ESL/ EFL teacher's course. 2 ed. Newbury: Heinle \& Heinle, 1999.

COMRIE, Bernard. Aspect: an introduction to the study of verbal aspect and related problems. Cambridge: Cambridge University Press, 1976.

CORÔA, Maria Luiza M. S. O tempo nos verbos do português: uma introdução à sua interpretação semântica. Brasília: Thesaurus, 1985.

DUTRA, Deise P. The acquisition of English root modality by non-native speakers. 1998. Tese (Doutorado em Lingüística) - College of Liberal Arts and Sciences, University of Florida.

EL-DASH, Linda G.; BUSNARDO, Joanne. Tempos verbais em inglês e português: escolhas pragmáticas a partir de aspectos semânticos. Trab. Ling. Aplic. Campinas, 40, p. 63-9, jul./dez. 2002.

ELLIS, R. The study of second language acquisition. 6th printing. Oxford: Oxford University Press, 1999.

GOHN, Carlos A. O "present perfect": dificuldades de conceitualização e de ensino. 1981. Dissertação (Mestrado em Lingüística) - Faculdade de Letras, Universidade Federal de Minas Gerais, Belo Horizonte.

HATCH, Evelyn, LAZARATON, Anne. The research manual: design and statistics for applied linguistics. Boston: Heinle \& Heinle Publishers, 1991.

KENNEDY, Graeme. An introduction to Corpus Linguistics. $2^{\text {nd }}$ imp. London \& New York: London, 1999.

KLEIN, Wolfgang. Second language acquisition (Cambridge Textbooks in Linguistics). (Zweitspracherwerb: eine Einführung, Athenäum Verlag, 1984) Traduzido para o inglês por Bohuslaw Jankowsky. Cambridge: Cambridge University Press, 1986.

LANGACKER, Ronald W. Grammar and conceptualization. Berlim: Mouton de Gruyter, 2000.

A Dynamic Usage-Based Model. In: BARLOW, Michael; KEMMER, Suzanne (Eds.). Usage-Based Models of Language. Stanford: Center for the Study of Language and Information, 2000, p.1-63. 
. Foundations of cognitive grammar: theoretical prerequisites. Stanford: Stanford University Press, 1999a. v.1.

. Foundations of cognitive grammar: descriptive application. Stanford: Stanford University Press, 1999b. v.2.

. Remarks on English aspect. In: HOPPER, Paul J. (Ed.). Tense aspect: between semantics and pragmatics. Amsterdam: John Benjamins, 1982. p.265-304.

LARSEN-FREEMAN, Diane; KUEHN, Tom; HACCIUS, Mark. Helping students make appropriate English verb tense-aspect choices. Tesol Journal, v.11, n.4. winter 2002.

LI, C.; THOMPSON, S.; THOMPSON, R. The discourse motivation for the perfect aspect: the Mandarin particle le. In: HOPPER, Paul J. (Ed.). Tense - aspect: between semantics and pragmatics. Amsterdam: John Benjamins, 1982. p.265-304.

MELLO, Heliana; DUTRA, Deise. The teaching of English aspectual categories to Brazilian Portuguese speakers: a cognitive grammar-based approach. Series B: Applied and Interdisciplinary Papers. Essen: LAUD, 2000 .

NUNAN, David. Research methods in language learning. $2^{\text {nd }}$ printing. Cambridge, Massachussets: Cambridge University Press, 1994.

OLIVEIRA, Aparecida de A. Um olhar cognitivo sobre o 'perfeito' da língua inglesa. In: MELLO, Heliana R. (Org.). Lingüistica Cognitiva: perspectivas. (No prelo).

SQUARTINI, Mario; BERTINETTO, Pier Marco. The simple and compound past in Romance languages. In: DAHL, Osten (Ed.). Tense and aspect in the languages of Europe. Berlim: Mouton de Gruyter, 2000.

WALKER, Ralph H. Teaching the present perfect tenses. Tesol Quarterly. Alamosa: Cybertech Enterprises, v.1, n. 4, p.17-30, 1997. CD-ROM. 


\section{ANEXO}

\section{TABELA 1}

Resumo das tentativas de uso do present perfect por informante - contagem por tipo.

Overuse é apresentado após “+”

\begin{tabular}{|c|c|c|c|c|c|c|c|c|c|c|c|}
\hline $\begin{array}{l}\text { CONTEXTO_- } \\
\text { INFORMANTE }\end{array}$ & $\begin{array}{l}\text { Redação } \\
\text { - acertos }\end{array}$ & \begin{tabular}{|l} 
Redação \\
- erros
\end{tabular} & $\begin{array}{l}\text { Role- } \\
\text { play - } \\
\text { acertos }\end{array}$ & $\begin{array}{l}\text { Role- } \\
\text { play - } \\
\text { erros }\end{array}$ & $\begin{array}{c}\text { Entrevista } \\
\text { - acertos }\end{array}$ & $\begin{array}{l}\text { Entrevista } \\
\text { - erros }\end{array}$ & $\begin{array}{l}\text { Total } \\
\text { acertos }\end{array}$ & $\begin{array}{c}\text { Porcentagem } \\
\text { acertos }\end{array}$ & $\begin{array}{l}\text { Total } \\
\text { erros }\end{array}$ & $\begin{array}{l}\text { Porcentagem } \\
\text { erros }\end{array}$ & $\begin{array}{l}\text { Total } \\
\text { ocorrências }\end{array}$ \\
\hline João & 0 & 1 & 0 & 7 & 0 & 3 & 0 & $0,00 \%$ & 11 & $100,00 \%$ & 11 \\
\hline Robson & 0 & 0 & 0 & 6 & 0 & 2 & 0 & $0,00 \%$ & 8 & $100,00 \%$ & 8 \\
\hline Fernando & 1 & 5 & 0 & 4 & 0 & 5 & 1 & $6,67 \%$ & 14 & $93,33 \%$ & 15 \\
\hline Luiz & 1 & $2+1$ & 0 & 7 & 0 & 3 & 1 & $7,14 \%$ & 13 & $92,86 \%$ & 14 \\
\hline Otávio & 0 & 2 & 1 & 6 & 0 & 4 & 1 & $7,70 \%$ & 12 & $92,30 \%$ & 13 \\
\hline Pedro & - & - & 1 & 6 & 0 & 1 & 1 & $12,50 \%$ & 7 & $87,50 \%$ & 8 \\
\hline lone & 0 & 1 & 1 & 2 & 0 & 3 & 1 & $14,29 \%$ & 6 & $85,71 \%$ & 7 \\
\hline Marcos & 1 & 0 & 0 & 8 & 1 & 4 & 2 & $14,29 \%$ & 12 & $85,71 \%$ & 14 \\
\hline Sérgio & 0 & 0 & 1 & 3 & 1 & 2 & 2 & $28,57 \%$ & 5 & $71,43 \%$ & 7 \\
\hline Lívia & 0 & 1 & 2 & 3 & 0 & 0 & 2 & $33,33 \%$ & 4 & $66,67 \%$ & 6 \\
\hline Bruce & 0 & 0 & 2 & $5+1$ & 3 & 1 & 5 & $41,67 \%$ & 7 & $58,33 \%$ & 12 \\
\hline Tiago & 1 & 0 & 4 & $5+1$ & 3 & 3 & 8 & $47,06 \%$ & 9 & $52,94 \%$ & 17 \\
\hline Sílvia & 0 & 0 & 5 & 2 & 1 & $2+1$ & 6 & $54,55 \%$ & 5 & $45,45 \%$ & 11 \\
\hline Rita & 1 & 1 & 7 & 3 & 2 & 0 & 10 & $71,43 \%$ & 4 & $28,57 \%$ & 14 \\
\hline Henrique & 0 & 0 & 4 & 3 & 4 & 0 & 8 & $72,73 \%$ & 3 & $27,27 \%$ & 11 \\
\hline Paulo & 1 & 0 & 7 & 1 & 2 & $1+1$ & 10 & $76,92 \%$ & 3 & $23,08 \%$ & 13 \\
\hline Luísa & 1 & 0 & 4 & 2 & 2 & 0 & 7 & $77,78 \%$ & 2 & $22,22 \%$ & 9 \\
\hline Fátima & 0 & 0 & 7 & $2+1$ & 4 & 0 & 11 & $78,57 \%$ & 3 & $21,43 \%$ & 14 \\
\hline
\end{tabular}


TABELA 2

Ocorrências de formas alternativas para contexto de present perfect Faixa $0 \%$ (total $=15$ tipos)

\begin{tabular}{|c|c|c|c|c|c|}
\hline CONTEXIG & & PERFECTI & & IMPERFECTIVO & \\
\hline INFORMANTE & Experiência (6) & $\begin{array}{l}\text { Resultado } \\
\text { atingido (4) }\end{array}$ & Evento recente $(0)$ & $\begin{array}{l}\text { Continuidade, hábito, } \\
\text { iteração [5] }\end{array}$ & $\begin{array}{l}\text { TIPOS POR } \\
\text { TAREFA }\end{array}$ \\
\hline João (role-plays) & $\begin{array}{l}1 \text { participate PS } \\
1 \text { have a TV } \\
\text { commercial PS }\end{array}$ & $\begin{array}{l}1 \text { arrive PS } \\
2 \text { change PS } \\
1 \text { see PS }\end{array}$ & 0 & $\begin{array}{l}2 \text { live PRS + for } \\
1 \text { do PRS + since }\end{array}$ & 7 \\
\hline João (redação) & 0 & 0 & 0 & 1 do [well] PRC +dur. & 1 \\
\hline $\begin{array}{l}\text { João } \\
\text { (entrevista) }\end{array}$ & $\begin{array}{l}1 \text { do } P S \\
1 \text { have a th. PS + } \\
\text { yet } \\
1 \text { go } P S+\text { once }\end{array}$ & 0 & 0 & 0 & 3 \\
\hline $\begin{array}{l}\text { Robson } \\
\text { (role-plays) }\end{array}$ & 1 do PS & $\begin{array}{l}1 \text { see PS } \\
1 \text { give PS }\end{array}$ & 0 & $\begin{array}{l}1 \text { live PRC + since } \\
1 \text { live PRS + since } \\
1 \text { be PRS + since }\end{array}$ & 6 \\
\hline $\begin{array}{l}\text { Robson } \\
\text { (entrevista) }\end{array}$ & $\begin{array}{l}1 \text { speak } B S+\text { once } \\
1 \text { be } P S+\text { never }\end{array}$ & 0 & 0 & 0 & 2 \\
\hline
\end{tabular}

\section{NOTAS:}

Abreviaturas de tempos verbais empregadas nesta e em outras tabelas: $\mathrm{BS}=$ forma base $;$ PRS $=$ Present Simple $;$ PRC $=$ Present Continuous $;$ PS $=$ Past Simple $; \mathrm{PC}=$ Past Continuous $; \mathrm{PP}=$ Past Perfect Simple $; \mathrm{PPC}=$ Past Perfect Continuous; (progr.) $=$ Present Perfect Continuous.

O número que aparece após o nome de cada categoria representa a quantidade de tipos na faixa de interlíngua.

A categoria 'Evento recente', nesta e nas demais tabelas, inclui as ocorrências com advérbio explícito, como just, recently, now, lately. 
TABELA 3

Ocorrências de present perfect $\mathrm{e}$ de formas alternativas Faixa de 1 a $20 \%$ (total $=54$ tipos)

\begin{tabular}{|c|c|c|c|c|c|c|}
\hline \multirow{2}{*}{$\begin{array}{l}\text { CONTEXTO } \longrightarrow \\
\text { INFORMANTE } \\
\downarrow\end{array}$} & \multicolumn{3}{|c|}{ PERFECTIVAS } & \multicolumn{2}{|c|}{ IMPERFECTIVAS } & \multirow{2}{*}{$\begin{array}{l}\text { TOTAL } \\
\text { DE } \\
\text { TIPOS } \\
\text { POR } \\
\text { TAREFA }\end{array}$} \\
\hline & Experiência (14) & $\begin{array}{l}\text { Resultado atingido } \\
\text { (16) }\end{array}$ & $\begin{array}{l}\text { Evento recente } \\
\text { (5) }\end{array}$ & $\begin{array}{l}\text { Continuidade, hábito, } \\
\text { iteração (16) }\end{array}$ & $\begin{array}{l}\text { Experiência } \\
\text { (3) }\end{array}$ & \\
\hline $\begin{array}{l}\text { Fernando } \\
\text { (entrevista erros) }\end{array}$ & $\begin{array}{l}1 \text { travel PS + never } \\
1 \text { meet PS } \\
1 \text { have PS }\end{array}$ & 0 & $\begin{array}{l}1 \text { start PS this } \\
\text { year }\end{array}$ & 1 be PRS & 0 & 5 \\
\hline $\begin{array}{l}\text { Fernando } \\
\text { (redação erros) }\end{array}$ & 0 & 1 make PS & 0 & $\begin{array}{l}3 \text { be PP } \\
1 \text { make PP } \\
1 \text { project PP }\end{array}$ & $\begin{array}{l}1 \text { be PS } \\
\text { [ever] }\end{array}$ & 5 \\
\hline $\begin{array}{l}\text { Fernando } \\
\text { (redação acertos) }\end{array}$ & 0 & 0 & 0 & 1 happen * (progr.) & 0 & 1 \\
\hline $\begin{array}{l}\text { Fernando (role- } \\
\text { plays erros) }\end{array}$ & 1 make PS & $\begin{array}{l}1 \text { come PP } \\
1 \text { see sth. PS }\end{array}$ & 0 & 1 live PRS + for & 0 & 4 \\
\hline $\begin{array}{l}\text { Luiz (entrevista } \\
\text { erros) }\end{array}$ & 1 travel BS+ frequ. & 0 & 0 & $\begin{array}{l}1 \text { try PRC+ since } \\
1 \text { study PRS+for }\end{array}$ & 0 & 3 \\
\hline $\begin{array}{l}\text { Luiz (role-plays } \\
\text { erros) }\end{array}$ & 1 see PS + frequ. & $\begin{array}{l}1 \text { leave PS } \\
1 \text { tell PS } \\
1 \text { see PS }\end{array}$ & $\begin{array}{l}1 \text { arrive PS + just } \\
1 \text { see PS + lately } \\
1 \text { buy PS } \\
\text { [recently] }\end{array}$ & 0 & 0 & 7 \\
\hline $\begin{array}{l}\text { Luiz (redação } \\
\text { erros) }\end{array}$ & $\begin{array}{l}1 \text { send PS } \\
1 \text { arrest PS }\end{array}$ & 0 & 0 & 0 & 0 & 2 \\
\hline $\begin{array}{l}\text { Luiz (redação } \\
\text { acertos) }\end{array}$ & 0 & 0 & 0 & 1 attack * (progr.) & 0 & 1 \\
\hline $\begin{array}{l}\text { Otávio (entrevista } \\
\text { erros) }\end{array}$ & $\begin{array}{l}1 \text { have practice PS + } \\
\text { since } \\
1 \text { practice PS + since }\end{array}$ & 0 & 0 & $\begin{array}{l}1 \text { have sth. PRS + not } \\
\text { until now }\end{array}$ & $\begin{array}{l}1 \text { like + all } \\
\text { my life BS }\end{array}$ & 4 \\
\hline $\begin{array}{l}\text { Otávio (role-plays } \\
\text { erros) }\end{array}$ & $\begin{array}{l}1 \text { work PS } \\
1 \text { be PS }\end{array}$ & $\begin{array}{l}1 \text { see PS } \\
1 \text { bring PS }\end{array}$ & 1 arrive PS + just & $\begin{array}{l}1 \text { live PRS + how } \\
\text { much time }\end{array}$ & 0 & 6 \\
\hline $\begin{array}{l}\text { Otávio (role-plays } \\
\text { acertos) }\end{array}$ & 0 & 0 & 0 & 1 receive + durativo & 0 & 1 \\
\hline $\begin{array}{l}\text { Otávio (redação } \\
\text { erros) }\end{array}$ & 0 & 0 & 0 & $\begin{array}{l}1 \text { be PRS + since } \\
1 \text { have PRS + since }\end{array}$ & 0 & 2 \\
\hline $\begin{array}{l}\text { Pedro (entrevista } \\
\text { erros) }\end{array}$ & 1 meet PS + never & 0 & 0 & 0 & 0 & 1 \\
\hline $\begin{array}{l}\text { Pedro (role-plays } \\
\text { erros) }\end{array}$ & 0 & $\begin{array}{l}1 \text { see } P S \\
1 \text { get PS } \\
1 \text { do } P S\end{array}$ & 0 & $\begin{array}{l}1 \text { live PRC + how } \\
\text { many time } \\
1 \text { live PRS + how } \\
\text { many years } \\
1 \text { act PRC }\end{array}$ & 0 & 6 \\
\hline $\begin{array}{l}\text { Pedro (role-plays } \\
\text { acertos) }\end{array}$ & 0 & 1see sb. & 0 & 0 & 0 & 1 \\
\hline $\begin{array}{l}\text { lone (entrevista } \\
\text { erros) }\end{array}$ & 0 & 0 & 0 & $\begin{array}{l}1 \text { study PRS + since } \\
1 \text { learn PRC }\end{array}$ & $\begin{array}{l}1 \text { study PS + } \\
\text { always }\end{array}$ & 3 \\
\hline $\begin{array}{l}\text { lone (redação } \\
\text { erros) }\end{array}$ & 0 & 0 & 0 & 0 & $\begin{array}{l}1 \text { be PS + } \\
\text { always }\end{array}$ & 1 \\
\hline
\end{tabular}


TABELA 3 (continuação)

Ocorrências de present perfect $\mathrm{e}$ de formas alternativas Faixa de 1 a $20 \%$ (total $=54$ tipos)

\begin{tabular}{|c|c|c|c|c|c|c|}
\hline CONTEXTQ $\longrightarrow$ & \multicolumn{3}{|c|}{ PERFECTIVAS } & \multicolumn{2}{|c|}{ IMPERFECTIVAS } & TOTAL DE \\
\hline INFORMANTE & Experiência & $\begin{array}{l}\text { Resultado } \\
\text { atingido }\end{array}$ & Evento recente & $\begin{array}{l}\text { Continuidade, hábito, } \\
\text { iteração }\end{array}$ & Experiência & $\begin{array}{l}\text { POR } \\
\text { TAREFA }\end{array}$ \\
\hline
\end{tabular}

\begin{tabular}{|c|c|c|c|c|c|c|}
\hline $\begin{array}{l}\text { lone (role-plays } \\
\text { erros) }\end{array}$ & 0 & 1 bring PS & 0 & 1 live PRS + [how long] & 0 & 2 \\
\hline $\begin{array}{l}\text { lone (role-plays } \\
\text { acertos) }\end{array}$ & 0 & 1 change & 0 & 0 & 0 & 1 \\
\hline $\begin{array}{l}\text { Marcos (role- } \\
\text { plays erros) }\end{array}$ & $\begin{array}{l}1 \text { act in a play } \\
\text { BS } \\
1 \text { do sth. PS }\end{array}$ & $\begin{array}{l}1 \text { notice sth. PRS } \\
1 \text { read sth. PS } \\
1 \text { happen PS } \\
1 \text { bring PRS }\end{array}$ & 0 & $\begin{array}{l}1 \text { there be PRS } \\
1 \text { live PRS + *how many } \\
\text { time }\end{array}$ & 0 & 8 \\
\hline $\begin{array}{l}\text { Marcos } \\
\text { (entrevista erros) }\end{array}$ & $\begin{array}{l}1 \text { see PS } \\
1 \text { listen PS }\end{array}$ & 1 develop PS & 1 stop PS + now & 0 & 0 & 4 \\
\hline $\begin{array}{l}\text { Marcos } \\
\text { (entrevista } \\
\text { acertos) }\end{array}$ & 0 & 1 develop a lot & 0 & 0 & 0 & 1 \\
\hline $\begin{array}{l}\text { Marcos (redação } \\
\text { acertos) }\end{array}$ & 0 & 0 & 0 & 1 see + durativo & 0 & 1 \\
\hline
\end{tabular}

TABELA 4

Ocorrências de present perfect $\mathrm{e}$ de formas alternativas Faixa de 21 a $40 \%$ (total $=13$ tipos)

\begin{tabular}{|c|c|c|c|c|c|}
\hline CONTEXTO_ & & PERFECTIVAS & & IMPERFECTIVAS & TOTAL DE \\
\hline INFORMANTE لاح & Experiência (3) & Resultado atingido (5) & Evento recente (2) & $\begin{array}{l}\text { Continuidade, hábito, } \\
\text { iteração (3) }\end{array}$ & POR TAREFA \\
\hline $\begin{array}{l}\text { sergio (entrevista } \\
\text { erros) }\end{array}$ & $\begin{array}{l}1 \text { have PS an } \\
\text { experience }\end{array}$ & 1 there be progress PS & 0 & 0 & 2 \\
\hline $\begin{array}{l}\text { Sérgio (entrevista } \\
\text { acertos) }\end{array}$ & 0 & 0 & 0 & $\begin{array}{l}1 \text { learn (progr.) + } \\
\text { since }\end{array}$ & 1 \\
\hline $\begin{array}{l}\text { Sérgio (role-plays } \\
\text { erros) }\end{array}$ & 0 & 1 bring PS & $\begin{array}{l}1 \text { there be PS + } \\
\text { recently }\end{array}$ & $\begin{array}{l}1 \text { live PRS + how } \\
\text { long }\end{array}$ & 3 \\
\hline $\begin{array}{l}\text { Sérgio (role-plays } \\
\text { acertos) }\end{array}$ & $1 \mathrm{do}^{*}+$ ever & 0 & 0 & 0 & 1 \\
\hline $\begin{array}{l}\text { Lívia (redação } \\
\text { erros) }\end{array}$ & 0 & 1 lose PS & 0 & 0 & 1 \\
\hline $\begin{array}{l}\text { Lívia (role-plays } \\
\text { erros) }\end{array}$ & $\begin{array}{l}1 \text { have an } \\
\text { experience PRS }\end{array}$ & 1 see PS & $\begin{array}{l}1 \text { buy PS } \\
\text { ["nowadays] }\end{array}$ & 0 & 3 \\
\hline $\begin{array}{l}\text { Lívia (role-plays } \\
\text { acertos) }\end{array}$ & 0 & 1 see $\mathrm{sb}$. & 0 & 1 travel a lot & 2 \\
\hline
\end{tabular}




\section{TABELA 5}

Ocorrências de present perfect e de formas alternativas Faixa de 41 a $60 \%$ (total = 34 tipos)

\begin{tabular}{|c|c|c|c|c|c|}
\hline CONTEXTO- & & PERFECTIVAS & & IMPERFECTIVAS & \\
\hline INFORMANTE $\downarrow$ & Experiência (10) & \begin{tabular}{|l|} 
Resultado \\
atingido (4)
\end{tabular} & Evento recente (3) & $\begin{array}{l}\text { Continuidade, hábito, iteração } \\
\text { (17) }\end{array}$ & POR TAREFA \\
\hline $\begin{array}{l}\text { Bruce (entrevista } \\
\text { erros) }\end{array}$ & 0 & 0 & 0 & 1 learn PRC + since & 1 \\
\hline $\begin{array}{l}\text { Bruce (entrevista } \\
\text { acertos) }\end{array}$ & $\begin{array}{l}1 \text { travel + yet } \\
1 \text { do + yet }\end{array}$ & 0 & 0 & 1 have classes + since & 3 \\
\hline $\begin{array}{l}\text { Bruce (role-plays } \\
\text { erros) }\end{array}$ & 0 & 0 & 0 & $\begin{array}{l}1 \text { live PRS + for } \\
1 \text { travel a lot BS + durativo } \\
1 \text { have a lot of visitors PS + } \\
\text { durativo } \\
1 \text { use [wear] PC } \\
1 \text { be PS [today] }\end{array}$ & 5 \\
\hline $\begin{array}{l}\text { Bruce (role-plays } \\
\text { acertos) }\end{array}$ & 1 do a play & 0 & 0 & 1 live (progr.) + for & 2 \\
\hline $\begin{array}{l}\text { Tiago (entrevista } \\
\text { erros) }\end{array}$ & $\begin{array}{l}1 \text { go PS + } \\
\text { freqüentativo }\end{array}$ & 0 & 0 & $\begin{array}{l}1 \text { study PRC + since } \\
1 \text { develop PRC+ durativo }\end{array}$ & 3 \\
\hline $\begin{array}{l}\text { Tiago (entrevista } \\
\text { acertos) }\end{array}$ & 1 happen before & 0 & 0 & $\begin{array}{l}1 \text { travel* (progr.) + freq. } \\
1 \text { travel (progr.) + freq. } \\
1 \text { study (progr.) + since }\end{array}$ & 3 \\
\hline $\begin{array}{l}\text { Tiago (role-plays } \\
\text { erros) }\end{array}$ & 0 & 1 see PS & $\begin{array}{l}1 \text { notice PRS + } \\
\text { recently }\end{array}$ & $\begin{array}{l}1 \text { live PRC + how long } \\
1 \text { work PRC + how long } \\
1 \text { travel PRC + since }\end{array}$ & 5 \\
\hline $\begin{array}{l}\text { Tiago (role-plays } \\
\text { acertos) }\end{array}$ & $\begin{array}{l}1 \text { make }^{*}+\text { ever } \\
1 \text { work }^{*}+\text { ever } \\
1 \text { represent }^{*}+ \\
\text { ever }\end{array}$ & 1 come $^{*}+$ already & 0 & 0 & 4 \\
\hline $\begin{array}{l}\text { Tiago (redação } \\
\text { acertos) }\end{array}$ & 0 & 0 & 0 & 1 be & 1 \\
\hline $\begin{array}{l}\text { Silvia (role-plays } \\
\text { acertos) }\end{array}$ & 1 act * + never & 0 & $\begin{array}{l}1 \text { marry + recently } \\
1 \text { change + } \\
\text { recently }\end{array}$ & $\begin{array}{l}1 \text { be + how long } \\
1 \text { act (progr.) }\end{array}$ & 5 \\
\hline $\begin{array}{l}\text { Sílvia (role-plays } \\
\text { erros) }\end{array}$ & 0 & $\begin{array}{l}1 \text { say PS + } \\
\text { already }\end{array}$ & 0 & 1 live PRS+ how long & 2 \\
\hline $\begin{array}{l}\text { Silvia (entrevista } \\
\text { erros) }\end{array}$ & $\begin{array}{l}1 \text { there be PS a } \\
\text { chance } \\
1 \text { tell PS }\end{array}$ & 0 & 0 & 0 & 2 \\
\hline $\begin{array}{l}\text { Silvia (entrevista } \\
\text { acertos) }\end{array}$ & 0 & 1 learn sth. & 0 & 0 & 1 \\
\hline
\end{tabular}


TABELA 6

Ocorrências de present perfect e de formas alternativas

Faixa de 61 a $80 \%$ (total $=46$ tipos)

\begin{tabular}{|c|c|c|c|c|c|c|}
\hline CONTEXTO & $\rightarrow$ & PERFECTIVAS & & IMPERFECTIVA & & TOTALDE \\
\hline INFORMANTE $\downarrow$ & Experiência (11) & $\begin{array}{l}\text { Resultado atingido } \\
\text { (9) }\end{array}$ & $\begin{array}{l}\text { Evento recente } \\
(6)\end{array}$ & $\begin{array}{l}\text { Continuidade, hábito, } \\
\text { iteração (19) }\end{array}$ & $\begin{array}{l}\text { Experiência } \\
\text { (1) }\end{array}$ & $\begin{array}{l}\text { POR } \\
\text { TAREFA }\end{array}$ \\
\hline $\begin{array}{l}\text { Paulo (entrevista } \\
\text { erros) }\end{array}$ & 1 have $P S+$ never & 0 & 0 & 0 & 0 & 1 \\
\hline $\begin{array}{l}\text { Paulo (entrevista } \\
\text { acertos) }\end{array}$ & 1 be on the net & 2 learn sth. & 0 & 0 & 0 & 2 \\
\hline $\begin{array}{l}\text { Paulo (role-plays } \\
\text { erros) }\end{array}$ & 0 & 1 happen PS & & 0 & 0 & 1 \\
\hline $\begin{array}{l}\text { Paulo (role-plays } \\
\text { acertos) }\end{array}$ & $\begin{array}{l}1 \text { take a course + } \\
\text { ever }\end{array}$ & 1 land + already & $\begin{array}{l}1 \text { buy [in the last } \\
\text { months] }\end{array}$ & $\begin{array}{l}1 \text { live (progr.) + for } \\
1 \text { live * (progr.) + for } \\
1 \text { travel (progr.) } \\
1 \text { wear (progr.) } \\
1 \text { receive * (progr.) }\end{array}$ & 0 & 7 \\
\hline $\begin{array}{l}\text { Paulo (redação } \\
\text { acertos) }\end{array}$ & 0 & 0 & 0 & 1 live (progr.) & 0 & 1 \\
\hline $\begin{array}{l}\text { Rita (redação } \\
\text { acertos) }\end{array}$ & 0 & 1 develop & 0 & 0 & 0 & 1 \\
\hline $\begin{array}{l}\text { Rita } \\
\text { erros) }\end{array}$ & 0 & & 0 & 1 do PPC & 0 & 1 \\
\hline $\begin{array}{l}\text { Rita (entrevista } \\
\text { acertos) }\end{array}$ & 0 & 0 & 0 & $\begin{array}{l}1 \text { think (progr.) }+ \text { for } \\
1 \text { teach (progr.) }+ \text { for }\end{array}$ & 0 & 2 \\
\hline $\begin{array}{l}\text { Rita (role-plays } \\
\text { erros) }\end{array}$ & $\begin{array}{l}1 \text { act PS } \\
1 \text { record PS }\end{array}$ & 0 & 0 & 1 be PRS + for & 0 & 3 \\
\hline $\begin{array}{l}\text { Rita (role-plays } \\
\text { acertos) }\end{array}$ & 1 hear + never & 0 & 1 arrive + just & $\begin{array}{l}1 \text { notice many people + } \\
\text { lately } \\
1 \text { happen + durativo } \\
1 \text { live (progr.) + for } \\
1 \text { see sb. + freq. }\end{array}$ & $\begin{array}{l}1 \text { hear sth. } \\
+ \text { always }\end{array}$ & 7 \\
\hline $\begin{array}{l}\text { Henrique (role- } \\
\text { plays erros) }\end{array}$ & 0 & 1 become BS & $\begin{array}{l}1 \text { buy PS } \\
\text { [recently] } \\
1 \text { start PS } \\
\text { [recently] }\end{array}$ & 0 & 0 & 3 \\
\hline $\begin{array}{l}\text { Henrique (role- } \\
\text { plays acertos) }\end{array}$ & $\begin{array}{l}1 \text { do } \\
1 \text { tape } \\
\text { commercials }\end{array}$ & 1 arrive + yet & 0 & 0 & 0 & 3 \\
\hline $\begin{array}{l}\text { Henrique } \\
\text { (entrevista } \\
\text { acertos) }\end{array}$ & $\begin{array}{l}1 \text { travel + yet } \\
1 \text { meet }\end{array}$ & 0 & 0 & $\begin{array}{l}1 \text { learn (progr.) + for } \\
1 \text { speak }^{*}+\text { for }\end{array}$ & 0 & 4 \\
\hline $\begin{array}{l}\text { Luísa (role-plays } \\
\text { erros) }\end{array}$ & 0 & $\begin{array}{l}1 \text { bring PS } \\
1 \text { help PS }\end{array}$ & 0 & 0 & 0 & 2 \\
\hline $\begin{array}{l}\text { Luisa (role-plays } \\
\text { acertos) }\end{array}$ & 1 talk $^{*}$ & 0 & $\begin{array}{l}1 \\
\text { nowadays }\end{array}$ & $\begin{array}{l}1 \text { be + since } \\
1 \text { live + how long }\end{array}$ & 0 & 4 \\
\hline $\begin{array}{l}\text { Luísa (entrevista } \\
\text { acertos) }\end{array}$ & 0 & 0 & 0 & $\begin{array}{l}1 \text { learn (progr.) }+ \text { since } \\
1 \text { improve (progr.) }\end{array}$ & 0 & 2 \\
\hline $\begin{array}{l}\text { Luisa (redação } \\
\text { acertos) }\end{array}$ & 0 & 0 & 0 & 1 listen (progr.) & 0 & 1 \\
\hline
\end{tabular}




\section{TABELA 6 (continuação)}

Ocorrências de present perfect $\mathrm{e}$ de formas alternativas

Faixa de 61 a $80 \%$

\begin{tabular}{l|l|l|l|l|l|l}
\hline CONTEXTO & $\rightarrow$ & \multicolumn{2}{c|}{ IMPERFECTIVAS } & $\begin{array}{l}\text { TOTALDE } \\
\text { TIPOS }\end{array}$ \\
\hline INFORMANTE & Experiência & Resultado atingido & Evento recente & $\begin{array}{l}\text { Continuidade, hábito, } \\
\text { iteração }\end{array}$ & Experiência & $\begin{array}{l}\text { POR } \\
\text { TAREFA }\end{array}$ \\
\hline
\end{tabular}

\begin{tabular}{|c|c|c|c|c|c|}
\hline $\begin{array}{l}\text { Fátima (role- } \\
\text { plays acertos) }\end{array}$ & $\begin{array}{l}1 \\
1 \text { be "to" a play }\end{array}$ & 0 & $\begin{array}{l}2 \text { notice }+ \text { [in the last } \\
\text { months] } \\
1 \text { get married [recently] }\end{array}$ & $\begin{array}{l}1 \text { see }+ \text { for } \\
1 \text { live (progr.) + how long } \\
1 \text { be }\end{array}$ & 0 \\
\hline $\begin{array}{l}\text { Fátima } \\
\text { (entrevista } \\
\text { acertos) }\end{array}$ & 1 know [meet] & 0 & 0 & $\begin{array}{l}1 \text { learn (progr.) + for } \\
1 \text { live (progr.) }+ \text { for } \\
1 \text { do +durativo }\end{array}$ & J \\
\hline
\end{tabular}


TABELA 7

Distribuição de formas e contextos ao longo da interlíngua

\begin{tabular}{|c|c|c|c|c|c|c|c|c|c|c|}
\hline \multirow{3}{*}{$\begin{array}{l}\text { Situações > } \\
\text { Contextos > } \\
\text { FAIXAS }\end{array}$} & \multicolumn{6}{|c|}{ PERFECTIVAS } & \multicolumn{4}{|c|}{ IMPERFECTIVAS } \\
\hline & \multicolumn{2}{|l|}{ Experiência } & \multicolumn{2}{|c|}{ Resultado atual } & \multicolumn{2}{|c|}{ Evento recente } & \multicolumn{2}{|l|}{ Continuação } & \multicolumn{2}{|l|}{ Experiência } \\
\hline & Adequado & Inadequado & Adequado & Inadequado & Adequado & Inadequado & Adequado & Inadequado & Adequado & II \\
\hline$\overline{0 \%}$ & 0 & 6 & 0 & 4 & 0 & 0 & 0 & 5 & 0 & \\
\hline Percentual & $0,00 \%$ & $100,00 \%$ & $0,00 \%$ & $100,00 \%$ & $0,00 \%$ & $0,00 \%$ & $0,00 \%$ & $100,00 \%$ & $0,00 \%$ & \\
\hline $1-20 \%$ & 0 & 14 & 3 & 13 & 0 & 5 & 4 & 12 & 0 & \\
\hline Percentual & $0,00 \%$ & $100,00 \%$ & $18,75 \%$ & $81,25 \%$ & $0,00 \%$ & $100,00 \%$ & $25,00 \%$ & $75,00 \%$ & $0,00 \%$ & \\
\hline $21-40 \%$ & 1 & 2 & 1 & 4 & 0 & 2 & 2 & 1 & 0 & \\
\hline Percentual & $33,33 \%$ & $66,67 \%$ & $20,00 \%$ & $80,00 \%$ & $0,00 \%$ & $100,00 \%$ & $66,67 \%$ & $33,33 \%$ & $0,00 \%$ & \\
\hline $41-60 \%$ & 7 & 3 & 2 & 2 & 2 & 1 & 6 & 11 & 0 & \\
\hline Percentual & $70,00 \%$ & $30,00 \%$ & $50,00 \%$ & $50,00 \%$ & $66,67 \%$ & $33,33 \%$ & $35,29 \%$ & $64,71 \%$ & $0,00 \%$ & \\
\hline $61-80 \%$ & 8 & 3 & 4 & 5 & 4 & 2 & 16 & 3 & 1 & \\
\hline Percentual & $72,73 \%$ & $27,27 \%$ & $44,44 \%$ & $55,56 \%$ & $66,67 \%$ & $33,33 \%$ & $84,21 \%$ & $15,79 \%$ & $100,00 \%$ & \\
\hline TOTAL: & $36,36 \%$ & $63,64 \%$ & $26,32 \%$ & $73,68 \%$ & $37,50 \%$ & $62,50 \%$ & $46,67 \%$ & $53,33 \%$ & $25,00 \%$ & \\
\hline Ocorrências & 16 & 28 & 10 & 28 & 6 & 10 & 28 & 32 & 1 & \\
\hline \multirow{3}{*}{\multicolumn{3}{|c|}{$\begin{array}{l}\text { TOTAL PERF. ACERTOS: } \\
\text { TOTAL PERF. ERROS: }\end{array}$}} & & $32,65 \%$ & 32 & & \multirow{3}{*}{\multicolumn{2}{|c|}{$\begin{array}{l}\text { TOTAL GERAL } \\
\text { POR TIPO: }\end{array}$}} & & \\
\hline & & & & $67,35 \%$ & 66 & & & & & \\
\hline & & & & & & & & & 162 & \\
\hline \multicolumn{3}{|c|}{ TOTAL IMPERF. ACERTOS: } & & $45,31 \%$ & 29 & & & & & \\
\hline \multicolumn{3}{|c|}{ TOTAL IMPERF. ERROS: } & & $54,69 \%$ & 35 & & & & & \\
\hline \multicolumn{4}{|c|}{ ACERTOS IMPERF. S/ "EXPERIÊNCIA": } & $46,67 \%$ & 28 & & & & & \\
\hline \multicolumn{4}{|c|}{ ERROS IMPERF. S/ "EXPERIÊNCIA" } & $53,33 \%$ & 32 & & & & & \\
\hline
\end{tabular}

NOTA: Cada unidade de ocorrência listada nesta planilha representa um tipo, sem distinção quanto ao uso de advérbios. 
TABELA 8

Aquisição em contextos de Experiência Perfectiva

\begin{tabular}{|c|c|c|c|c|c|c|c|c|c|}
\hline \multirow[b]{2}{*}{ FAIXAS } & \multicolumn{2}{|c|}{ CORRETOS } & \multicolumn{2}{|c|}{ PAST SIMPLE } & \multicolumn{2}{|c|}{ BASE } & \multicolumn{2}{|c|}{ PRESENT SIMPLE } & \multirow{2}{*}{$\begin{array}{l}\text { IN } \\
\text { AC } \\
\end{array}$} \\
\hline & c/ ADV. & S/ADV. & c/ ADV. & s/ADV. & c/ADV. & s/ADV. & c/ ADV. & s/ADV. & \\
\hline $0 \%$ & 0 & 0 & 3 & 3 & 1 & 0 & 0 & 0 & \\
\hline S/ total & $0,00 \%$ & $0,00 \%$ & $42,86 \%$ & $42,86 \%$ & $14,29 \%$ & $0,00 \%$ & $0,00 \%$ & $0,00 \%$ & \\
\hline Parcial & $0,00 \%$ & $0,00 \%$ & $50,00 \%$ & $50,00 \%$ & $100,00 \%$ & $0,00 \%$ & $0,00 \%$ & $0,00 \%$ & \\
\hline 1 A $20 \%$ & 0 & 0 & 4 & 10 & 0 & 2 & 0 & 0 & \\
\hline S/ total & $0,00 \%$ & $0,00 \%$ & $25,00 \%$ & $62,50 \%$ & $0,00 \%$ & $12,50 \%$ & $0,00 \%$ & $0,00 \%$ & \\
\hline Parcial & $0,00 \%$ & $0,00 \%$ & $28,57 \%$ & $71,43 \%$ & $0,00 \%$ & $=100,00 \%$ & $0,00 \%$ & $0,00 \%$ & \\
\hline 21 A $40 \%$ & 1 & 0 & 0 & 1 & 0 & 0 & 0 & 1 & \\
\hline S/ total & $33,33 \%$ & $0,00 \%$ & $0,00 \%$ & $33,33 \%$ & $0,00 \%$ & $0,00 \%$ & $0,00 \%$ & $33,33 \%$ & \\
\hline Parcial & $100,00 \%$ & $0,00 \%$ & $0,00 \%$ & $100,00 \%$ & $0,00 \%$ & $0,00 \%$ & $0,00 \%$ & $100,00 \%$ & \\
\hline 41 A $60 \%$ & 7 & 1 & 0 & 3 & 0 & 0 & 0 & 0 & \\
\hline S/ total & $63,64 \%$ & $9,09 \%$ & $0,00 \%$ & $27,27 \%$ & $0,00 \%$ & $0,00 \%$ & $0,00 \%$ & $0,00 \%$ & \\
\hline$P$ arcial & $87,50 \%$ & $12,50 \%$ & $0,00 \%$ & $100,00 \%$ & $0,00 \%$ & $0,00 \%$ & $0,00 \%$ & $0,00 \%$ & \\
\hline 61 A $80 \%$ & 3 & 5 & 1 & 2 & 0 & 0 & 0 & 0 & \\
\hline S/ total & $27,27 \%$ & $45,45 \%$ & $9,09 \%$ & $18,18 \%$ & $0,00 \%$ & $0,00 \%$ & $0,00 \%$ & $0,00 \%$ & \\
\hline Parcial & $37,50 \%$ & $62,50 \%$ & $33,33 \%$ & $66,67 \%$ & $0,00 \%$ & $0,00 \%$ & $0,00 \%$ & $0,0 ९ \%$ & \\
\hline Total por & & & & & & & & & TC \\
\hline categoria & 11 & 6 & 8 & 19 & 1 & 2 & 0 & 1 & \\
\hline
\end{tabular}

Ocorrências por falta

NOTA: As tabelas de número 8 a 12 apresentam uma contagem por tipo, com distinção quanto à presença ou à ausência de advérbios e, portanto, apresentam diferenças quantitativas em relação às tabelas anteriores. 
TABELA 9

Aquisição em contextos de Resultado Atual

\begin{tabular}{|c|c|c|c|c|c|c|c|c|c|c|c|}
\hline \multirow[b]{2}{*}{ FAIXA } & \multicolumn{2}{|c|}{ CORRETOS } & \multicolumn{2}{|c|}{ PAST SIMPLE } & \multicolumn{2}{|c|}{ BASE } & \multicolumn{2}{|c|}{ PRESENT SIMPLE } & \multicolumn{2}{|c|}{ PAST PERFECT } & \multirow{2}{*}{$\begin{array}{l}\text { INDD } \\
\text { ACEF }\end{array}$} \\
\hline & c/ ADV. & s/ ADV. & cl ADV. & s/ ADV. & cl ADV. & s/ ADV. & cl ADV. & s/ ADV. & cl ADV. & s/ ADV. & \\
\hline $0 \%$ & 0 & 0 & 0 & 4 & 0 & 0 & 0 & 0 & 0 & 0 & \\
\hline S/ total & $0,00 \%$ & $0,00 \%$ & $0,00 \%$ & $100,00 \%$ & $0,00 \%$ & $0,00 \%$ & $0,00 \%$ & $0,00 \%$ & $0,00 \%$ & $0,00 \%$ & \\
\hline Parcial & $0,00 \%$ & $0,00 \%$ & $0,00 \%$ & $100,00 \%$ & $0,00 \%$ & $0,00 \%$ & $0,00 \%$ & $0,00 \%$ & $0,00 \%$ & $0,00 \%$ & \\
\hline 1 A $20 \%$ & 0 & 3 & 0 & 10 & 0 & 0 & 0 & 2 & 0 & 1 & \\
\hline S/ total & $0,00 \%$ & $18,75 \%$ & $0,00 \%$ & $62,50 \%$ & $0,00 \%$ & $0,00 \%$ & $0,00 \%$ & $12,50 \%$ & $0,00 \%$ & $6,25 \%$ & \\
\hline Parcial & $0,00 \%$ & $100,00 \%$ & $0,00 \%$ & $100,00 \%$ & $0,00 \%$ & $0,00 \%$ & $0,00 \%$ & $100,00 \%$ & $0,00 \%$ & $100,00 \%$ & \\
\hline $21 \mathrm{~A} 40 \%$ & 0 & 1 & 0 & 4 & 0 & 0 & 0 & 0 & 0 & 0 & \\
\hline S/ total & $0,00 \%$ & $20,00 \%$ & $0,00 \%$ & $80,00 \%$ & $0,00 \%$ & $0,00 \%$ & $0,00 \%$ & $0,00 \%$ & $0,00 \%$ & $0,00 \%$ & \\
\hline Parcial & $0,00 \%$ & $100,00 \%$ & $0,00 \%$ & $100,00 \%$ & $0,00 \%$ & $0,00 \%$ & $0,00 \%$ & $0,00 \%$ & $0,00 \%$ & $0,00 \%$ & \\
\hline $41 \mathrm{~A} 60 \%$ & 1 & 1 & 1 & 1 & 0 & 0 & 0 & 0 & 0 & 0 & 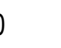 \\
\hline S/ total & $25,00 \%$ & $25,00 \%$ & $25,00 \%$ & $25,00 \%$ & $0,00 \%$ & $0,00 \%$ & $0,00 \%$ & $0,00 \%$ & $0,00 \%$ & $0,00 \%$ & \\
\hline Parcial & $50,00 \%$ & $50,00 \%$ & $50,00 \%$ & $50,00 \%$ & $0,00 \%$ & $0,00 \%$ & $0,00 \%$ & $0,00 \%$ & $0,00 \%$ & $0,00 \%$ & \\
\hline $61 \mathrm{~A} 80 \%$ & 2 & 2 & 0 & 4 & 0 & 1 & 0 & 0 & 0 & 0 & ) \\
\hline S/ total & $22,22 \%$ & $22,22 \%$ & $0,00 \%$ & $44,44 \%$ & $0,00 \%$ & $11,11 \%$ & $0,00 \%$ & $0,00 \%$ & $0,00 \%$ & $0,00 \%$ & \\
\hline Parcial & $50,00 \%$ & $50,00 \%$ & $0,00 \%$ & $100,00 \%$ & $0,00 \%$ & $100,00 \%$ & $0,00 \%$ & $0,00 \%$ & $0,00 \%$ & $0,00 \%$ & \\
\hline $\begin{array}{l}\text { Total por } \\
\text { categoria: }\end{array}$ & 3 & 7 & 1 & 23 & 0 & 1 & 0 & 2 & 0 & 1 & TO' \\
\hline
\end{tabular}

Ocorrências

por falta 
TABELA 10

Aquisição em contextos de Evento Recente

\begin{tabular}{|c|c|c|c|c|c|}
\hline \multirow[b]{2}{*}{ FAIXAS } & \multirow{2}{*}{$\begin{array}{l}\text { CORRETOS } \\
\text { c/ ADV. }\end{array}$} & \multirow{2}{*}{\begin{tabular}{|l} 
PAST SIMPLE \\
c/ ADV.
\end{tabular}} & \multirow{2}{*}{$\begin{array}{l}\text { PRESENT SIMPLE } \\
\text { c/ ADV. }\end{array}$} & & \multirow{2}{*}{$\begin{array}{l}\text { Ocorrências } \\
\text { por falta }\end{array}$} \\
\hline & & & & & \\
\hline$\overline{0 \%}$ & 0 & 0 & 0 & & $\mathbf{0}$ \\
\hline S/ total & $0,00 \%$ & $0,00 \%$ & $0,00 \%$ & & \\
\hline 1 A $20 \%$ & 0 & 5 & 0 & & 5 \\
\hline S/ total & $0,00 \%$ & $100,00 \%$ & $0,00 \%$ & & \\
\hline $21 \mathrm{~A} 40 \%$ & 0 & 2 & 0 & & 2 \\
\hline $\mathrm{S} /$ total & $0,00 \%$ & $100,00 \%$ & $0,00 \%$ & & \\
\hline $41 \mathrm{~A} 60 \%$ & 2 & 0 & 1 & & 3 \\
\hline S/ total & $66,67 \%$ & $0,00 \%$ & $33,33 \%$ & & \\
\hline 61 A $80 \%$ & 4 & 2 & 0 & & 6 \\
\hline $\mathrm{S} /$ total & $66,67 \%$ & $33,33 \%$ & $0,00 \%$ & & \\
\hline $\begin{array}{l}\text { Total por } \\
\text { categoria: }\end{array}$ & 6 & 9 & 1 & TOTAL & 16 \\
\hline
\end{tabular}


TABELA 11

Aquisição em contextos de Continuação

\begin{tabular}{|c|c|c|c|c|c|c|c|c|c|}
\hline \multirow[b]{2}{*}{ FAIXAS } & \multicolumn{2}{|c|}{ PRES. P. SIMPLE } & \multicolumn{2}{|c|}{ PRES. P. CONT. } & \multicolumn{2}{|c|}{ PRES. CONT. } & \multicolumn{2}{|c|}{ PRES. SIMPLE } & \multirow{2}{*}{$\frac{P A S}{c / A D}$} \\
\hline & c/ ADV. & s/ ADV. & c/ ADV. & s/ ADV. & c/ ADV. & s/ ADV. & c/ ADV. & s/ ADV. & \\
\hline$\overline{0 \%}$ & $\frac{1}{0}$ & 0 & 0 & 0 & 2 & 0 & $\overline{3}$ & 0 & \\
\hline $\mathrm{S} /$ total & $0,00 \%$ & $0,00 \%$ & $0,00 \%$ & $0,00 \%$ & $40,00 \%$ & $0,00 \%$ & $60,00 \%$ & $0,00 \%$ & \\
\hline Parcial & $0,00 \%$ & $0,00 \%$ & $0,00 \%$ & $0,00 \%$ & $100,00 \%$ & $0,00 \%$ & $100,00 \%$ & $0,00 \%$ & \\
\hline 1 A $20 \%$ & 2 & 0 & 0 & 2 & 2 & 2 & 4 & 2 & \\
\hline S/ total & $11,76 \%$ & $0,00 \%$ & $0,00 \%$ & $11,76 \%$ & $11,76 \%$ & $11,76 \%$ & $23,53 \%$ & $11,76 \%$ & \\
\hline Parcial & $100,00 \%$ & $0,00 \%$ & $0,00 \%$ & $100,00 \%$ & $50,00 \%$ & $50,00 \%$ & $66,67 \%$ & $33,33 \%$ & \\
\hline 21 A $40 \%$ & 0 & 1 & 1 & 0 & 0 & 0 & 1 & 0 & \\
\hline S/ total & $0,00 \%$ & $33,33 \%$ & $33,33 \%$ & $0,00 \%$ & $0,00 \%$ & $0,00 \%$ & $33,33 \%$ & $0,00 \%$ & \\
\hline Parcial & $0,00 \%$ & $100,00 \%$ & $100,00 \%$ & $0,00 \%$ & $0,00 \%$ & $0,00 \%$ & $100,00 \%$ & $0,00 \%$ & \\
\hline $41 \mathrm{~A} 60 \%$ & 2 & 1 & 1 & 2 & 6 & 0 & 1 & 0 & \\
\hline S/ total & $11,76 \%$ & $5,88 \%$ & $5,88 \%$ & $11,76 \%$ & $35,29 \%$ & $0,00 \%$ & $5,88 \%$ & $0,00 \%$ & \\
\hline Parcial & $66,67 \%$ & $33,33 \%$ & $33,33 \%$ & $66,67 \%$ & $100,00 \%$ & $0,00 \%$ & $100,00 \%$ & $0,00 \%$ & \\
\hline 61 a $80 \%$ & 7 & 2 & 4 & 6 & 0 & 1 & 1 & 0 & \\
\hline S/ total & $31,82 \%$ & $9,09 \%$ & $18,18 \%$ & $27,27 \%$ & $0,00 \%$ & $4,55 \%$ & $4,55 \%$ & $0,00 \%$ & \\
\hline Parcial & $77,78 \%$ & $22,22 \%$ & $40,00 \%$ & $60,00 \%$ & $0,00 \%$ & $100,00 \%$ & $100,00 \%$ & $0,00 \%$ & \\
\hline Total por & & & & & & & & & \\
\hline categoria: & 11 & 4 & 6 & 10 & 10 & 3 & 10 & 2 & \\
\hline
\end{tabular}

Continua 
TABELA 11 (Continuação)

Aquisição em contextos de Continuação

\begin{tabular}{|c|c|c|c|c|c|c|c|c|c|}
\hline & \multicolumn{4}{|c|}{ PAST PERF. SIMPLE PAST SIMPLE } & \multicolumn{2}{|c|}{ BASE } & \multicolumn{3}{|c|}{ PAST CONTINUOUSIÍNDICE } \\
\hline & $\mathrm{c} / \mathrm{ADV}$ & s/ADV. & $\mathrm{c} / \mathrm{ADV}$ & s/ ADV. & $\mathrm{c} / \mathrm{ADV}$. & s/ADV. & $\mathrm{c} / \mathrm{ADV}$. & s/ ADV. & ACERTOS \\
\hline $0 \%$ & 0 & 0 & 0 & 0 & 0 & 0 & 0 & 0 & \\
\hline $\mathrm{S} /$ total & $0,00 \%$ & $0,00 \%$ & $0,00 \%$ & $0,00 \%$ & $0,00 \%$ & $0,00 \%$ & $0,00 \%$ & $0,00 \%$ & 0,00 \\
\hline Parcial & $0,00 \%$ & $0,00 \%$ & $0,00 \%$ & $0,00 \%$ & $0,00 \%$ & $0,00 \%$ & $0,00 \%$ & $0,00 \%$ & \\
\hline 1 a $20 \%$ & 0 & 3 & 0 & 0 & 0 & 0 & 0 & 0 & \\
\hline $\mathrm{S} /$ total & $0,00 \%$ & $17,65 \%$ & $0,00 \%$ & $0,00 \%$ & $0,00 \%$ & $0,00 \%$ & $0,00 \%$ & $0,00 \%$ & 23,53 \\
\hline Parcial & $0,00 \%$ & $100,00 \%$ & $0,00 \%$ & $0,00 \%$ & $0,00 \%$ & $0,00 \%$ & $0,00 \%$ & $0,00 \%$ & \\
\hline 21 a $40 \%$ & 0 & 0 & 0 & 0 & 0 & 0 & 0 & 0 & \\
\hline $\mathrm{S} /$ total & $0,00 \%$ & $0,00 \%$ & $0,00 \%$ & $0,00 \%$ & $0,00 \%$ & $0,00 \%$ & $0,00 \%$ & $0,00 \%$ & 66,67 \\
\hline Parcial & $0,00 \%$ & $0,00 \%$ & $0,00 \%$ & $0,00 \%$ & $0,00 \%$ & $0,00 \%$ & $0,00 \%$ & $0,00 \%$ & \\
\hline 41 a $60 \%$ & 0 & 0 & 2 & 0 & 1 & 0 & 0 & 1 & \\
\hline $\mathrm{S} /$ total & $0,00 \%$ & $0,00 \%$ & $11,76 \%$ & $0,00 \%$ & $5,88 \%$ & $0,00 \%$ & $0,00 \%$ & $5,88 \%$ & 35,29 ' \\
\hline Parcial & $0,00 \%$ & $0,00 \%$ & $100,00 \%$ & $0,00 \%$ & $100,00 \%$ & $0,00 \%$ & $0,00 \%$ & $100,00 \%$ & \\
\hline 61 a $80 \%$ & 0 & 0 & 0 & 0 & 0 & 0 & 0 & 0 & \\
\hline $\mathrm{S} /$ total & $0,00 \%$ & $0,00 \%$ & $0,00 \%$ & $0,00 \%$ & $0,00 \%$ & $0,00 \%$ & $0,00 \%$ & $0,00 \%$ & 86,36 \\
\hline Parcial & $0,00 \%$ & $0,00 \%$ & $0,00 \%$ & $0,00 \%$ & $0,00 \%$ & $0,00 \%$ & $0,00 \%$ & $0,00 \%$ & \\
\hline $\begin{array}{l}\text { Total por } \\
\text { Categoria: }\end{array}$ & 0 & 3 & 2 & 0 & 1 & 0 & 0 & 1 & TOTAL: \\
\hline
\end{tabular}


TABELA 12

Aquisição em contextos de Experiência Imperfectiva

\begin{tabular}{|c|c|c|c|c|c|c|c|c|}
\hline \multirow[b]{2}{*}{ FAIXAS } & \multicolumn{2}{|l|}{ CORRETOS } & \multicolumn{2}{|c|}{ PAST SIMPLE } & \multicolumn{2}{|l|}{ BASE } & \multirow{2}{*}{$\begin{array}{l}\text { Indice } \\
\text { acertos }\end{array}$} & \multirow{2}{*}{$\begin{array}{l}\text { Ocorr } \\
\text { por fe }\end{array}$} \\
\hline & c/ ADV. & s/ ADV. & c/ ADV. & s/ADV. & c/ ADV. & s/ ADV. & & \\
\hline $0 \%$ & 0 & 0 & 0 & 0 & 0 & 0 & & \\
\hline Parcial & $0,00 \%$ & $0,00 \%$ & $0,00 \%$ & $0,00 \%$ & $0,00 \%$ & $0,00 \%$ & & \\
\hline S/ total & $0,00 \%$ & $0,00 \%$ & $0,00 \%$ & $0,00 \%$ & $0,00 \%$ & $0,00 \%$ & $0,00 \%$ & \\
\hline 1 A $20 \%$ & 0 & 0 & 2 & 0 & 1 & 0 & & \\
\hline Parcial & $0,00 \%$ & $0,00 \%$ & $100,00 \%$ & $0,00 \%$ & $100,00 \%$ & $0,00 \%$ & & \\
\hline S/ total & $0,00 \%$ & $0,00 \%$ & $66,67 \%$ & $0,00 \%$ & $33,33 \%$ & $0,00 \%$ & $0,00 \%$ & \\
\hline 21 A 40\% & 0 & 0 & 0 & 0 & 0 & 0 & & \\
\hline Parcial & $0,00 \%$ & $0,00 \%$ & $0,00 \%$ & $0,00 \%$ & $0,00 \%$ & $0,00 \%$ & & \\
\hline S/ total & $0,00 \%$ & $0,00 \%$ & $0,00 \%$ & $0,00 \%$ & $0,00 \%$ & $0,00 \%$ & $0,00 \%$ & \\
\hline $41 \mathrm{~A} 60 \%$ & 0 & 0 & 0 & 0 & 0 & 0 & & \\
\hline Parcial & $0,00 \%$ & $0,00 \%$ & $0,00 \%$ & $0,00 \%$ & $0,00 \%$ & $0,00 \%$ & & \\
\hline S/ total & $0,00 \%$ & $0,00 \%$ & $0,00 \%$ & $0,00 \%$ & $0,00 \%$ & $0,00 \%$ & $0,00 \%$ & \\
\hline 61 A $80 \%$ & 1 & 0 & 0 & 0 & 0 & 0 & & \\
\hline Parcial & $100,00 \%$ & $0,00 \%$ & $0,00 \%$ & $0,00 \%$ & $0,00 \%$ & $0,00 \%$ & & \\
\hline S/ total & $100,00 \%$ & $0,00 \%$ & $0,00 \%$ & $0,00 \%$ & $0,00 \%$ & $0,00 \%$ & $100,00 \%$ & \\
\hline Total por & & & & & & & TOTAL: & \\
\hline Categoria: & 1 & 0 & 2 & 0 & 1 & 0 & & \\
\hline
\end{tabular}

